Discussion Paper No. 835

\title{
FREE ENTRY, REGULATORY COMPETITION, AND GLOBALIZATION
}

\author{
Kaz Miyagiwa \\ Yasuhiro Sato
}

March 2012

The Institute of Social and Economic Research Osaka University

6-1 Mihogaoka, Ibaraki, Osaka 567-0047, Japan 


\title{
Free entry, regulatory competition, and globalization*
}

\author{
Kaz Miyagiwa $^{\dagger} \quad$ Yasuhiro Sato $^{\ddagger}$
}

March 5, 2012

\begin{abstract}
This paper examines the optimal entry policy towards oligopoly in a globalized world. In an open economy free entry is socially suboptimal, but corrective tax policy to curb entry proves insufficient unless internationally harmonized. Thus, while conferring the gains from trade, globalization prevents countries from pursuing the optimal entry policy. When countries are small, the gains from trade dominate the losses from a suboptimal entry policy, but as markets grow the result is reversed, making trade inferior to autarky. Therefore, the need for tax harmonization grows as the world economy grows. This paper also contributes to the international tax competition literature through the discovery of the reverse home market effect.
\end{abstract}

JEL classification: F15, H21, H77, L13

Keywords: Entry Policy, Excessive entry, Globalization, Regulatory competition

\section{Introduction}

The idea that free entry leads to a social optimum has long been cherished as an irrefragable truth in economics. However, this shibboleth has recently been challenged by a number of researchers. ${ }^{1}$

${ }^{*}$ We thank participants at NARSC, ARSC and the JSPS Kakenhi Kiban (A) seminar held at Kwansei Gakuin University for helpful discussions and comments. Special thanks go to Jacques-F. Thisse for stimulating conversations that set this project in motion. We acknowledge the financial support by the JSPS Grants-in-Aid for Scientific Research (S, A, B, and C) and the MEXT Grant-in-Aid for Young Scientists (B).

${ }^{\dagger}$ Florida International University and Emory and Osaka Unviersities, e-mail: kmiyagiwa@gmail.com

‡Osaka University, e-mail: ysato@econ.osaka-u.ac.jp

${ }^{1}$ Also see von Weizsacker (1980), Perry (1984), and Suzumura and Kiyono (1987). 
In particular, Mankiw and Whinston (1986) have demonstrated that free entry results in too much competition in oligopoly if entry reduces output per firm at the margin. This condition, dubbed the "business stealing effect," is so mild that it holds in a wide variety of situations; in particular, in Cournot competition. While the Mankiw-Whinston analysis pertains to a closed economy, with the world getting fast globalized, it is natural to wonder whether their results carry over intact to a globalized environment.

In a global economy the question whether unrestricted entry results in too much competition and, if so, what constitutes an optimal intervention policy - can be approached from the perspective of an individual country or the entire world. The added dimensionality points to a possible conflict and policy coordination dilemma among individual countries. It is possible, for example, that entry is excessive for the whole world but too little from an individual country's perspective. Even if all countries agree that entry is excessive, it is another matter whether they can correct the entry problem.

A global economy confronts individual countries with yet another policy dilemma, which concerns the choice between free trade and autarky. On the one hand, the result of Mankiw and Whinston (1986) shows that a country in autarky can attain a social optimum by restricting entry. On the other hand, by the result of Brander and Krugman (1985) an open economy enjoys the gains from trade under oligopoly with free entry. But, if free trade prevents it from instituting the socially optimal entry policy, a country faces this fundamental trade-off: retreating to autarky, a country can pursue the optimal entry policy but forgoes the gains from trade, whereas it faces the opposite dilemma when it remains open to trade.

The objective of the present paper is to address these policy issues brought about by globalization. To that end, we consider a two-country partial equilibrium model of Cournot competition with free entry. While Mankiw and Whinston (1986) consider regulating the number of active firms directly with a governmental edict, here we explore the corrective role of corporate income tax as an indirect measure to control entry. The two approaches are fully equivalent, provided that the tax revenues are rebated back to society in lump-sum fashion. However, our approach has the added advantage of relating to the growing literature on international tax competition. 
Our main findings can be summarized as follows. We find first that in a globalized economy free entry also results in excessive competition. Thus, each country has the unilateral incentive to tax domestic firms to curb entry. However, taxation of domestic firm promotes entry in the foreign country. As entry by foreign firms undermines the efficacy of domestic tax policy, each country chooses too low a tax rate relative to when there are no such spillovers. Hence, in a global economy entry remains excessive even with government interventions. Our analysis implies that international tax policy harmonization is indispensable for the achievement of a social optimum in a globalized economy.

As for the dilemma concerning the choice between free trade and autarky, the answer depends on market size. When markets are small, the gains from trade dominate the losses from excessive entry, so globalization benefits countries. However, when both markets grow sufficiently large, the above result is reversed, and autarky becomes welfare-dominant. Thus, the need for coordinated tax policy grows as the world economy grows.

These results are obtained analytically under the simplifying assumptions that include symmetry, linearity and arbitrarily low transports. Relaxing these conditions makes the model analytically intractable, but numerical analysis yields the same results, demonstrating that the basic mechanism yielding our analytical results is at work in more general settings. In addition, when we relax the symmetry assumption, the numerical analysis gives us two new results. First, the model exhibits the reverse home market effect, that is, the large country hosts a smaller number of national firms relative to its market size compared with the smaller country. This contrasts sharply with the standard result in economic geography and trade (see e.g., Krugman 1980; Fujita et al. 1999). Second, the larger country chooses a lower tax relative to the smaller country. Further, this tax difference across countries widens as the counties becomes more asymmetric in size. These results also contrast sharply with the well-known result in the standard tax competition literature.

By the last two results this paper also contributes to the strand of the tax competition literature that goes back to Wilson (1986) and Zodrow and Mieszkowski (1986). These authors have shown that unilateral taxation of internationally mobile factors increases the tax base in the other country through factor flights. In the present study, factors are internationally immobile but similar results 
emerge as corporate taxation affects the distribution of national firms across countries. This paper is however more closely related to the new strand of literature investigating international capital tax competition under imperfect competition. For example, Ludema and Wooton (2000) and Haufler and Wooton (2010) have examined how the market (population) size affects the tax rates and welfare under Cournot competition. While the numbers of firms are fixed in those studies, here they are determined endogenously through entry. Thus, our model complements those studies by examining the effect of globalization on welfare as globalization affects firms' distributions.

The organization of this paper is as follows. In Section 2, we explain the general model. Section 3 examines the case of symmetric demands and negligible trade costs. Section 4 considers the case of symmetric linear demands and also the effects of trade costs. Section 5 examines the case of asymmetric markets. Section 6 concludes.

\section{The general model}

This is a two-country partial equilibrium model. Call two countries (regions) East and West. Each country has a large number of potential firms capable of producing the goods in question, of which $m_{i}$ firms actually enter in country $i(i=e, w)$. Firms are immobile across national borders, so there is no confusion in referring to a representative firm domiciled in country $i$ as firm $i$. The goods are considered homogeneous. Let $p_{i}\left(Q_{i}\right)$ denote the (inverse) demand in country i, where $Q_{i}$ is total quantity sold in country $i$. Assume continuous differentiability with first derivatives denoted by $p_{i}^{\prime}<0$. (Primes denote derivatives.)

On the production side, firms face constant marginal cost $c$ and incur setup cost $k_{i}$ on entry. Firms also pay transport cost $t$ for each unit they export. Transport cost is low enough for firms to always export positive quantities, the condition to be made more precise below. If $q_{i j}$ denotes the quantity sold by firm $i$ in country $j(i, j=e, w)$, industry supply in market $i$ equals

$$
Q_{i}=m_{i} q_{i i}+m_{j} q_{j i}
$$


Firms $i$ pay the corporate income $\operatorname{tax} \tau_{i}$ to their home country $i$, earning the net profit ${ }^{2}$

$$
\pi_{i}=\left(1-\tau_{i}\right)\left[\left(p_{i}\left(Q_{i}\right)-c\right) q_{i i}+\left(p_{j}\left(Q_{j}\right)-c-t\right) q_{i j}\right]-k_{i}
$$

The entry cost $k_{i}$ is assumed to increase as more firms operate in country $i$, so

$$
k_{i}=k\left(m_{i}\right)
$$

with $k_{i}^{\prime}>0 .^{3}$ This assumption implies that entry entails negative externalities or congestion. Such is the case, for example, if land supply is limited so firm concentration drives up the land rent, an important component of setup cost.

Firms consider the two national markets segmented, and choose home and foreign sales, $q_{i i}$ and $q_{i j}$, separately to maximize total profits (2), given all other firms' outputs. The first-order conditions for firm $i$ are

$$
\begin{array}{r}
p_{i}\left(Q_{i}\right)+p_{i}^{\prime}\left(Q_{i}\right) q_{i i}-c=0 \\
p_{j}\left(Q_{j}\right)+p_{j}^{\prime}\left(Q_{j}\right) q_{i j}-c-t=0 .
\end{array}
$$

The second-order conditions are assumed to hold; i. e.,

$$
\left.2 p_{i}^{\prime}\left(Q_{i}\right)+p_{i}^{\prime \prime}\left(Q_{i}\right) q_{i i}<0 \quad \text { (for all } i \text { and } j\right)
$$

The first-order conditions can be arranged to yield the equilibrium outputs:

$$
\begin{aligned}
& q_{i i}^{*}=-\frac{p_{i}\left(Q_{i}\right)-c}{p_{i}^{\prime}\left(Q_{i}\right)} \equiv q_{i i}\left(Q_{i}\right) \\
& q_{i j}^{*}=-\frac{p_{j}\left(Q_{j}\right)-c-t}{p_{j}^{\prime}\left(Q_{j}\right)} \equiv q_{i j}\left(Q_{j}\right) .
\end{aligned}
$$

\footnotetext{
${ }^{2}$ We consider tax on operating profits of firms. The result is much the same even if we tax the profit net of entry cost.

${ }^{3}$ This assumption allows us to determine the distribution of firms between countries at $t=0$. Alternatively, we can make entry cost constant, solve the model with $t>0$ and take a limit of $t \rightarrow 0$ to obtain the same results. If instead entry entails positive externalities (i.e., $k_{i}^{\prime}<0$ ), free entry induces infinitely many firms to enter. Our assumption excludes this possibility.
} 
On substitution, the equilibrium profit can be expressed as

$$
\pi_{i}\left(Q_{i}, Q_{j}, \tau_{i}\right)=\left(1-\tau_{i}\right)\left[-\frac{\left(p_{i}\left(Q_{i}\right)-c\right)^{2}}{p_{i}^{\prime}\left(Q_{i}\right)}-\frac{\left(p_{j}\left(Q_{j}\right)-c-t\right)^{2}}{p_{j}^{\prime}\left(Q_{j}\right)}\right]-k_{i}
$$

If $m_{i}$ is treated as a continuous variable as is standard in the literature, free entry implies zero net profit for all active firms, and hence:

$$
\pi_{i}\left(Q_{i}, Q_{j}, m_{i}, m_{j}, \tau_{i}\right)=0, \quad i, j=e, w
$$

Further, substituting from (4) into (1) yields

$$
Q_{i}=m_{i} q_{i i}\left(Q_{i}\right)+m_{j} q_{j i}\left(Q_{i}\right) \quad(\text { for all } i \text { and } j)
$$

Equations (6) and (7) form a four-equation system which can be solved for equilibrium industry supplies, $Q_{e}, Q_{w}$, and the equilibrium numbers of active firms, $m_{e}$ and $m_{w}$. The equilibrium firm outputs $q_{i i}$ and $q_{i j}$ follow from (4).

Governments impose $\operatorname{tax} \tau_{i}$ and returns the tax revenues in lump-sum fashion to domestic consumers. Thus, country $i$ 's national welfare $W_{i}$ comprises the consumer surplus, the total domestic industry profit and the tax revenue and expressed as:

$$
W_{i}=\int_{0}^{Q_{i}} p_{i}(x) d x-p_{i}\left(Q_{i}\right) Q_{i}+\left(p_{i}\left(Q_{i}\right)-c\right) Q_{i i}+\left(p_{j}\left(Q_{j}\right)-c-t\right) Q_{i j}-m_{i} k_{i}
$$

where the first two terms represent consumer surplus, the next two measure the sum of firm profits and tax revenues, while the final term is the total setup cost. The tax revenues and rebates do not figure explicitly because they cancel each other in aggregation, implying the absence of fiscal externality, i.e., there is no externality due to changes in the tax base. However, tax policy entails an entirely new type of externality through changes in distribution of firms across countries and affects the degree of excess in entry in the world. 


\section{$3 \quad$ Entry and corporate income tax in a global economy}

If there is no trade, free entry results in too much competition but it is easy to check that excessive entry can be corrected, and a social optimum achieved, with corporate income tax, as implied by the Mankiw-Whinston analysis. Our objective is to revisit this policy prescription in a global economy. Thus, we begin our analysis with the question: is competition excessive in an open economy as in a closed economy? An extension to a global economy, however, raises two essential questions that do not surface in the analysis of a closed economy. First, if there is too much competition, does each country have the unilateral incentive to tax its firms? Second, if each country has such an incentive, can two countries attain a social optimum without harmonizing their tax policies?

In this section we address these questions under the assumptions that market demands are symmetric and transport cost $t$ are arbitrarily small (which we relax later). Use (1) and (4) to write industry supply in each market as

$$
Q_{i}=-\frac{m_{i}\left(p\left(Q_{i}\right)-c\right)+m_{j}\left(p\left(Q_{i}\right)-c-t\right)}{p^{\prime}\left(Q_{i}\right)}
$$

As $t$ approaches zero, this expression simplifies to

$$
Q_{i}=-\frac{M\left(p\left(Q_{i}\right)-c\right)}{p^{\prime}\left(Q_{i}\right)}
$$

where $M=m_{e}+m_{w}$ denotes the total number of active firms in the world. Differentiation yields:

$$
\begin{aligned}
\frac{\partial Q_{i}}{\partial m_{i}} & =-\frac{p\left(Q_{i}\right)-c}{(1+M) p^{\prime}\left(Q_{i}\right)+Q_{i} p^{\prime \prime}\left(Q_{i}\right)}>0 \\
\frac{\partial Q_{j}}{\partial m_{i}} & =-\frac{p\left(Q_{j}\right)-c}{(1+M) p^{\prime}\left(Q_{j}\right)+Q_{j} p^{\prime \prime}\left(Q_{j}\right)}>0 \\
\frac{\partial q_{i i}}{\partial m_{i}} & =\frac{\partial q_{j i}}{\partial m_{i}}=\left[-1+\frac{p^{\prime \prime}\left(Q_{i}\right)\left(p\left(Q_{i}\right)-c\right)}{\left(p^{\prime}\left(Q_{i}\right)\right)^{2}}\right] \frac{\partial Q_{i}}{\partial m_{i}}<0 \\
\frac{\partial q_{i j}}{\partial m_{i}} & =\frac{\partial q_{j j}}{\partial m_{i}}=\left[-1+\frac{p^{\prime \prime}\left(Q_{j}\right)\left(p\left(Q_{j}\right)-c\right)}{\left(p^{\prime}\left(Q_{j}\right)\right)^{2}}\right] \frac{\partial Q_{j}}{\partial m_{i}}<0 .
\end{aligned}
$$

The last two inequalities confirm the presence of the Mankiw-Whinston (1986) business-stealing 
effect in a global economy, namely, entry reduces the existing firm's outputs at home and abroad at the margin.

The free-entry conditions are now given by

$$
\left(p\left(Q_{i}\right)-c\right) q_{i i}+\left(p\left(Q_{j}\right)-c\right) q_{i j}=\frac{k\left(m_{i}\right)}{1-\tau_{i}}
$$

Differentiating (11) and using the derivative results in (10) leads to our first result:

Proposition 1 Suppose demands are symmetric and transport costs are negligible. When a country raises its tax, domestic firms exit by a greater number than foreign firms enter, causing the total number of active firms in the world to decline.

Proof: See Appendix A

The presence of the business-stealing effect implies excessive entry for a social planner. The marginal entrant increases total supply which is good for society but causes other firms to contract output which is bad for society. However, the marginal entrant does not take the second effect into consideration when making the entry decision. Thus, free entry leads to too much competition.

Given that entry is excessive in a global economy, we turn to our next question: does each country have the unilateral incentive to control entry by its domestic firms? We answer this question by evaluating $\partial W_{i} / \partial \tau_{i}$ at $\tau_{i}=\tau_{j}=0$. Our finding is given in

Proposition 2 Suppose that demands are symmetric and transport costs are negligible. When there are no initial taxes, each country has the unilateral incentive to introduce corporate income $\operatorname{tax}$.

Proof: See Appendix B

Proposition 2 holds because by proposition 1 taxation in one country reduces the total number of firms in the world, and improves national welfare, given excess entry. Hence, each country has the unilateral incentive to intervene. Given such incentives for intervention, the next question 
we ask is: can countries attain a social optimum when acting unilaterally? In other words, what is the total effect of the two taxes levied unilaterally? To answer this question, we consider the three-stage game, in which each country first chooses the tax rate unilaterally to maximize its welfare, given the other county's tax rate, then firms decide whether to enter and finally entrant firms engage in Cournot competition in the manner described above. We look for the symmetric subgame-perfect Nash equilibrium of this game.

To understand the welfare properties of the equilibrium of this game, consider the effect of an exogenous change in the tax rate in country $i$ on world welfare, namely:

$$
\frac{\partial\left(W_{i}+W_{j}\right)}{\partial \tau_{i}}=\frac{\partial W_{i}}{\partial \tau_{i}}+\frac{\partial W_{j}}{\partial \tau_{i}}
$$

As each country chooses the tax rate to maximize its welfare, we set $\partial W_{i} / \partial \tau_{i}=0$ in the above expression and observe that the following holds at a symmetric equilibrium:

$$
\left.\partial\left(W_{i}+W_{j}\right)\right|_{\text {symmetric equilibrium }}=\left.\frac{\partial W_{j}}{\partial \tau_{i}}\right|_{\text {symmetric equilibrium }} .
$$

Thus, the sign of $\partial W_{j} /\left.\partial \tau_{i}\right|_{\text {symmetric equilibrium }}$ evaluated at the equilibrium tax rate indicates whether the equilibrium tax rate is too high or too low relative to a global optimum. Appendix $\mathrm{C}$ shows that this derivative is positive, implying that the equilibrium tax rate is too low, i.e., there is still too much entry after taxation. This important result is noted in

Proposition 3 In a global economy, when both countries impose the optimal corporate taxes without harmonization, entry remains excessive.

Proof: See Appendix C.

This proposition says that uncoordinated taxation fails to completely remove excessive entry. To understand the intuition recall that unilateral taxation decreases the number of domestic firms by proposition 1 , reducing competition and benefiting the taxing country. However, also by proposition 1 , tax in one country promotes entry in the foreign country, thereby partially offsetting the 
beneficial effect of taxation. Unable to fully appropriate the benefits of its tax policy, a country chooses too low a tax rate relative to what it would choose in the absence of such policy spillovers.

It is straightforward to show that internationally harmonized tax policy can attain the global social optimum. Since the world itself is a close economy and two countries are symmetric, each country's welfare can be expressed as the function of the total number of firms $M$ in the world. Then, as in Mankiw-Whinston (1986) there exists the optimal number of firms in the world. This and the first-order conditions determine the corresponding firm output and hence the firm's net profit. The zero profit condition then uniquely determines the required tax needed for a social optimum.

In summary, free entry results in too much competition in a global economy as it does in a closed economy, so that each country has the incentive to tax its domestic firms to combat the problem of worldwide excessive entry. However, due to policy spillovers the optimal taxation for each country, when chosen unilaterally, proves insufficient, leaving entry still excessive the world over. Thus our analysis implies international harmonization of tax policy is indispensable for a social optimal from the word's perspective.

\section{Symmetric linear demand and transport cost}

In this section we assume linear demands and entry cost to get sharper results. We consider the demands of the form:

$$
p_{i}=A-\frac{Q_{i}}{n}
$$

where $A$ is demand intercept and $n$ is the number of consumers in each country (the assumption of symmetric demand is retained) and use the entry cost function

$$
k_{i}=\frac{k m_{i}}{2} .
$$


where $k>0$ is constant. This entry cost function is consistent with the simple land market model with fixed land supply. ${ }^{4}$ Choose the unit so that $A-c=1$. Then, country- $i$ welfare can be expressed as

$$
W_{i}=n\left[\frac{\left(1-p_{i}\right)^{2}}{2}+s_{i}\right]+m_{i} \pi_{i}
$$

where $s$ is the tax revenue per firm.

Cournot competition yields the following equilibrium outputs and prices

$$
\begin{aligned}
& q_{w w}=n p_{w}, \quad q_{w e}=n\left(p_{e}-t\right) \\
& q_{e e}=n p_{e}, \quad q_{e w}=n\left(p_{w}-t\right) \\
& p_{w}=\frac{1+t m_{e}}{1+M}, \quad p_{e}=\frac{1+t m_{w}}{1+M} .
\end{aligned}
$$

In the current setting, trade occurs if and only if $p_{i}>t$. This condition is written $1 /\left(1+m_{i}\right)>t$. Also, Cournot competition makes sense only if $m_{i} \geq 1 .^{5}$ These two requirements combine to yield the following regularity condition, assumed to hold throughout the analysis:

$$
\frac{1}{2} \geq \frac{1}{1+m_{i}}>t
$$

Substituting (13) into the firm's profit (2), we obtain these free entry conditions:

$$
\begin{aligned}
\phi_{w} & =\frac{k m_{w}}{2\left(1-\tau_{w}\right)} \\
\phi_{e} & =\frac{k m_{e}}{2\left(1-\tau_{e}\right)},
\end{aligned}
$$

${ }^{4}$ This entry cost has another interpretation: Suppose there are $\bar{M}$ potential firms and they are heterogeneous with respect to entry cost. $\bar{M}$ is assumed to be exogenous and sufficiently large. If the entry cost is represented by $\kappa / h$ where $h$ follows a Pareto distribution with a shape parameter equal to one and with support $[\kappa,+\infty)$, there is a threshold level $h^{*}$ such that firms with higher $h$ than $h^{*}$ enter the market and firms with lower $h$ than $h^{*}$ do not enter. The entry cost for a firm $h^{*}$ becomes a linear function of $m_{i}$ (more precisely, $k m_{i} / 2$, where $k$ is now defined as $k=2 \kappa / \bar{M})$. Pareto distributions are often assumed in models of firm heterogeneity; see Helpman et al. (2004), for instance.

${ }^{5} \mathrm{We}$ assume that there is no integer problem. 
where $\phi_{i}$ is defined by

$$
\phi_{i} \equiv n\left(\frac{1+t m_{j}}{1+M}\right)^{2}+n\left[\frac{1-t\left(1+m_{j}\right)}{1+M}\right]^{2}, \quad i \neq j
$$

Two equations in (14) determine the number of firms $m_{e}$ and $m_{w}$ for given tax rates $\tau_{e}$ and $\tau_{w}$. Using these relations, we obtain the next proposition, which generalizes proposition 2 to the case of non-negligible trade costs.

Proposition 4 In the case of symmetric linear demands, with no initial taxes, each country has the unilateral incentive to introduce corporate income tax at any non-prohibitive transport cost $t$.

Proof: See Appendix D.

As shown by Brander and Krugman (1983), there are gains from trade under Cournot competition with free entry. However, since countries cannot completely eliminate excess entry without tax policy harmonization, the equilibrium outcome is suboptimal for an open economy. In contrast, in autarky a country can attain a social optimum with respect to entry but forgoes the gains from trade. Because of this trade-off, it is not obvious whether free trade welfare-dominates autarky.

We investigate this issue using the linear model of this section. Our finding is summarized in the next proposition. ${ }^{6}$

Proposition 5 Suppose demands are linear and identical across countries. Assume that transport costs are negligible.

(A) When countries are small, the gains from trade dominate the losses from excess entry in magnitude, and hence trade welfare-dominates autarky.

(B) When countries are sufficiently large, the result in (A) is reversed so autarky welfaredominates trade.

Proof: See Appendix G.

\footnotetext{
${ }^{6}$ Appendix E shows the existence and uniqueness of symmetric Nash equilibrium of the tax game, and Appendix $\mathrm{F}$ describes the case of autarky.
} 
We only outline the proof of the proposition here (the complete proof is in appendix G). Let the superscripts $a$ and $o$ denote the equilibrium value in autarky and open economy, respectively. Key to the proof are the following two welfare expressions. The first one

$$
W_{i}^{a}=\underbrace{\frac{N m^{a}\left(2+m^{a}\right)}{4\left(1+m^{a}\right)^{2}}}_{\equiv S_{i}^{a}}-\underbrace{\frac{k\left(m^{a}\right)^{2}}{2}}_{\equiv C_{i}^{a}}
$$

gives the optimal symmetric welfare under autarky, where each government can attain a social optimum while forgoing the gains from trade. The second

$$
W_{i}^{o}=\underbrace{\frac{N m^{o}\left(1+m^{o}\right)}{\left(1+2 m^{o}\right)^{2}}}_{\equiv S_{i}^{o}}-\underbrace{\frac{k\left(m^{o}\right)^{2}}{2}}_{\equiv C_{i}^{o}} .
$$

measures the equilibrium symmetric welfare under free trade, in which each country captures the gains from trade but fails to eliminate excess entry. In these expressions, $S_{i}^{l}$ represents the gross social surplus, i.e., the sum of consumer surplus and profits inclusive of entry costs, and $C_{i}^{l}$ represents the total cost of entry.

Let $N$ denote the total number of consumers in the world. By symmetry $N=2 n$. A calculation shows that $m^{a}=1$ and $m^{o} \approx 1.1571$ at $N=16 k$; see (E2) and (F4) in the appendix. Since there must be at least one active firm in each country, our model makes sense only if $N \geq 16 k$, which we assume throughout the remainder of the analysis. Then, computation yields $W_{i}^{o} / W_{i}^{a} \approx 1.186$ at $N=16 k$, that is, when $N$ takes on its minimum value, each country's welfare is greater with trade than in autarky. However, this welfare ranking is reversed when $N$ is sufficiently large. To show that, consider the ratios

$$
\begin{aligned}
\frac{S_{i}^{o}}{S_{i}^{a}} & =\frac{4\left(1+1 / m^{a}\right)^{2}\left(1+1 / m^{o}\right)}{\left(1+2 / m^{a}\right)\left(2+1 / m^{o}\right)^{2}} \\
\frac{C_{i}^{o}}{C_{i}^{a}} & =\left(\frac{m^{o}}{m^{a}}\right)^{2} .
\end{aligned}
$$

(E2) and (F4) in the appendix imply that $\lim _{N \rightarrow+\infty} m^{a}=+\infty$ and $\lim _{N \rightarrow+\infty} m^{o}=+\infty$ but $\lim _{N \rightarrow+\infty} m^{o} / m^{a}=+\infty$. Therefore, as $N$ goes to infinity the surplus ratio $S_{i}^{o} / S_{i}^{a}$ converges to 
one, but the entry cost ratio $C_{i}^{o} / C_{i}^{a}$ grows without bounds. These two limit results imply that $W_{i}^{o} / W_{i}^{a}<1$ for a sufficiently large $N$, that is, each country is better off in autarky than in an open economy when the markets are sufficiently large. In the next section we demonstrate these results by numerical analysis.

Proposition 5 implies that, as the world economy grows, countries are more likely to be worse off in a globalized economy than in autarky. The intuition can be explained as follows. In the presence of entry cost firms face decreasing average cost so they are more efficient in a larger market. As a result, there are a fewer firms in a large country than a small country relative to the market size. In the case of linear demands, if the market grows by ten percent, the number of firms grows roughly by five percent. Trade doubles the market size, allowing firms to decrease average cost, and hence proves more valuable when the country is small. In contrast, if the country is large, it can realize substantial scale economies without relying so much on trade, so trade is relatively unimportant. Therefore, when the world economy is small, the gains from trade dominate the welfare loss from the suboptimal entry policy, whereas when the world is sufficiently large, the countries are better off giving up the gains from trade and instead pursuing the optimal entry policy in autarky. ${ }^{7}$ Proposition 5 therefore implies that the need for international tax harmonization increases as the world economy grows.

We now examine how robust our results are in the presence of non-negligible trade cost. The model is too cumbersome analytically, so we resort to numerical analysis. Our simulation results are presented in the four panels of figure 1, where we set the entry cost parameter equal to $k=1$ (so that entry cost equals $k_{i}=m_{i} / 2$ ) and each country's consumer population equal to $n=20{ }^{8}$ The numerical results are consonant with our analytical results, demonstrating the robustness of our results in the presence of non-negligible transport cost.

[Figure 1 around here]

Begin with the analysis of the relationship between excessive entry and trade cost. To that end,

\footnotetext{
${ }^{7}$ This result is unaltered qualitatively if we focus on per capita welfare (i.e., $W_{i} / n$ ) because we can readily see that $\mathbf{s g n}\left[W_{i}^{o} / n-W_{i}^{a} / n\right]=\mathbf{s g n}\left[W_{i}^{o}-W_{i}^{a}\right]$. See also Figure $1-(\mathrm{d})$.

${ }^{8}$ The cases where $k=0.5$ and1.5 yield similar results.
} 
represent the measure of excess in entry by the ratio $\left(M^{o} / M^{*}\right)$, where $M^{o}$ denotes the number of the total firms in an open economy with uncoordinated tax policy and $M^{*}$ the optimal number of firms that maximizes world welfare $W_{e}+W_{w}$. Panel 1-(a) shows that entry remains excessive even at non-negligible transport cost, thereby demonstrating the results of proposition 3 in the presence of transport cost. The panel also shows that the degree of excess in entry falls as transport cost rises. The intuition underlying this result is that, the higher the trade cost, the less open the countries, and hence unilateral tax does not induce as much entry in the foreign country. The weaker spillover effect makes domestic tax policy more effective in combating excessive entry, and the degree of excess in entry declines.

The next three panels concern the impact of trade on welfare under optimal tax policy, i. e., the difference in welfare between trade and autraky. Panel 1-(b) illustrates the effect of changes in market size (population) on the impact of trade on welfare at four different transport costs $(t=0$, $0.001,0.025,0.05)$. The trade costs are differentiated by the thickness of the curves; the thicker the curve, the higher the transport cost. Each curve first rises from one but eventually falls below zero, indicating that at small populations trade welfare-dominates autarky while at larger populations the converse is true. Thus, panel 1-(b) shows that proposition 5 holds at non-negligible transport costs in our numerical analysis. The underlying intuition is already discussed following proposition 5.

Panel 1-(b) also shows that a rise in transport cost reduces the benefits of trade at any given population. The intuition is the same as above; at higher trade cost, the spillover effect is weaker, and the tax policy more efficacious, thereby making autarky more attractive relative to trade. This result is more evident in panel 1-(c), where transport cost continuously changes while the population is fixed at three levels $(n=10,15,20$, i.e., $N=20,30,40)$. Finally, in panel 1 -(d) we evaluate the welfare effect of population changes in per capita terms. As with the corresponding aggregate measures in panel 1-(b), trade welfare-dominates autarky at small populations but the converse holds at larger populations. The only difference is that here, unlike in panel 1-(b), the benefits of trade per capita monotonically decline as the world population grows. 


\section{Asymmetric countries}

In this section we relax the symmetry assumption in market size. Assume without loss of generality that West has the fraction $\theta$ of the world population, where $1>\theta \geq 1 / 2$, i.e., West is the larger of the two countries. For simulation purposes the total (world) population is set at $N=30$, the entry cost parameter at $k=1$, and the transport cost at $t=0.025 .^{9}$

[Figure 2 around here]

The first question we address concerns the relationship between the population distribution and the firm distribution across countries. We begin by evaluating the ratio $\left(m_{w} / m_{e}\right) /[\theta /(1-\theta)]$ in the absence of taxes. The numerator of this expression measures the number of domestic firms located in West relative to East, while the denominator measures the relative population residing in West. If this ratio equals one, there is a perfect proportionality between the two distributions across countries; that is, each country has the same numbers of domestic firms per capita. Figure 2 shows, however, this ratio to be less than one at all relevant values of $\theta$, meaning that a large country has a fewer domestic firms per capital compared with a small country. This result contrasts sharply with the home market effect, the well-known result in the standard literature stating that a large country has a proportionately greater number of domestic firms. Since our result reverses this statement, we call ours the reverse home market effect.

The reverse home market effect has a simple intuitive explanation. We already noted earlier that in the presence of entry cost a larger market is served by a relatively fewer and more efficient firms than a smaller market due to the decreasing average cost. The same intuition holds in a global economy. The reverse home market effect is also featured in the work of Sato and Thisse (2007). There, however, it arises for the entirely different reason; competition among firms in the local labor market, and hence is distinct from ours. 10

\footnotetext{
${ }^{9}$ We checked the robustness of the results against different parameter values: $N=20,40, k=0.5,1.5$ and $t=0.001,0.05$. Under these alternative parameter values, the results are unaltered qualitatively.

${ }^{10}$ Head et al. (2002) analyze three models involving increasing returns and trade in order to assess the robustness of the home market effect against alternative modeling assumptions. They find that, when the traded goods are differentiated between trading countries and not among firms, even a fairly standard trade model can exhibit the reverse home market effect.
} 
[Figure 3 around here]

We next turn to the relationship between the market size asymmetry and the optimal tax rates. Figure 3 depicts how the equilibrium tax rates change as $\theta$ increases from 0.5 to 0.8 (the large country gets larger). The large country's tax rate is represented by the solid line, and the small country's tax rate by the dashed line. Figure 3 reveals two important results. First, the thick line lies below the dashed line in the figure, indicating that the tax rates are lower in the large country at all $\theta>1 / 2$. Second, as the population shifts more to the larger country, the tax falls monotonically in the large country while rising monotonically in the small country. Thus, as countries become more asymmetric, the tax rates diverge further.

These results can be explained intuitively as follows. Due to the reverse home market effect, the large country has a fewer firms relative its population compared with the small country, implying that entry is less excessive in the large country. Therefore, there is less need for corrective tax in the larger country and hence the tax is lower there.

These results contrast sharply with the well-known result in the standard tax competition literature, which predicts that the tax rates are higher in the large country than in the small country. ${ }^{11}$ However, it is interesting to note that this standard result is not always borne out empirically. For example, Devereux et al. (2002) have found mixed results in their study of the effective corporate tax rates among OECD countries. According to this study, for instance, larger countries such as Germany, Japan, and the United States choose higher effective corporate taxes than their smaller counterparts, Austria, Finland and Sweden, in consonance with the standard literature, whereas smaller countries such as Belgium and Greece also set higher taxes than their larger counterparts, France and the United Kingdom, contradicting the standard result in the literature; see figure 7 in Devereux et al. (2002). Our analysis may offer a possible explanation why empirical findings are inconclusive.

\footnotetext{
${ }^{11}$ For earlier contributions, see Bucovetsky (1991) and Wilson (1991) on perfectly competitive product markets. More recent studies, using models of imperfect competition, find that in the presence of the home market effect the large country set a higher tax rate than the small country to capture the "agglomeration rent." See Andersson and Forslid (2003), Baldwin et al. (2003), Baldwin and Krugman (2004), Borck and Pflüger (2006), Haufler and Wooton (2010), Kind et al. (20009, Ludema and Wooton (2000) and Ottaviano and van Ypersele (2005). Haufler and Pflüer (2004) examine the commodity tax competition under monopolistic competition.
} 
[Figure 4 around here]

Finally, we examine the effect of country asymmetry on the impact of trade on welfare, both in aggregate and per capita terms. In figure 4, the benefits of trade are represented by the solid line for the large country and by the dashed line for the small country. As the large country gets larger, the benefits of trade decrease for the large country, but increase for the small country in both terms. The intuition is now familiar. Since the larger country can realize the substantial economies of scale without the market-expanding effect of trade, tending to the entry problem takes precedence over accessing a small foreign market. As the distribution becomes more lopsided, the benefits of trade further decline in the large country, while the converse holds in the small country.

\section{Concluding remarks}

In a close economy free entry leads to too much competition in oligopolistic industry, but a social optimum is attainable with corrective tax policy. This paper reconsiders this Mankiw-Whinston (1986) result in an open economy. We first show that without government interventions the problem of excessive entry inheres in a globalized world. More importantly, in a global economy corrective tax measures cannot completely eliminate excessive entry without international tax harmonization, because taxation in one country promotes entry in the foreign country, partially offsetting the effect of the tax and reducing the efficacy of the tax policy. For this reason, countries set taxes too low relative to a global optimum, leading to a suboptimal outcome.

However, globalization also generates the gains from trade as shown by Brander and Krugman (1983). Thus, the overall welfare effect of globalization hinges on the balance between the gains from trade and the welfare loss from the inability to pursue the optimal entry policy in an open economy. When countries are small, the gains from trade dominate so trade raises aggregate welfare. When countries are large, however, the result reverses itself, implying that autarky is better than trade. Thus, our analysis indicates that coordinated tax policy is essential for a global optimum and that the need for tax harmonization is increased as the world economy grows.

These results are obtained under the symmetry assumption. Although we also consider the case 
of unequal populations, in the real world countries are heterogeneous in other dimensions, such as technologies and capital endowments, as well. Our analysis should be extended to such asymmetric environments. Our model can also be extended to more than two countries. Such an extension allows us to study the welfare implications of partial coordination i.e., coordination by a subset of countries. Another question one can ask is whether the multiplicity of countries diminishes or increases the degree of excessive entry the world over. A third possible extension of our analysis is to other types of imperfect competition such as Bertrand and monopolistic competition. While Bertrand models are likely to behave similarly, monopolistic competition models can behave quite differently. Finally, it is worth investigating the effects of sequential entry as well as sequential tax decisions, as globalization may have different impacts on the leader and the follower. These extensions require separate treatment and are left for future research.

\section{Appendix A: Proof of Proposition 1.}

The free entry condition (11) forms a two-equation system that is solvable for $Q_{e}$ and $Q_{w}$ in terms of $m_{e}$ and $m_{w}$ for given $\tau_{e}$ and $\tau_{w}$. Denote the derivative of the left-hand side of (11) with respect to $m_{j}$ by $\beta_{i j}$ and define $B$ by

$$
B \equiv\left(\begin{array}{cc}
\beta_{11} & \beta_{12} \\
\beta_{21} & \beta_{22}
\end{array}\right)
$$

where

$$
\begin{aligned}
& \beta_{11} \equiv q_{i i} p^{\prime}\left(Q_{i}\right) \frac{\partial Q_{i}}{\partial m_{i}}+\left(p\left(Q_{i}\right)-c\right) \frac{\partial q_{i i}}{\partial m_{i}}+q_{i j} p^{\prime}\left(Q_{j}\right) \frac{\partial Q_{j}}{\partial m_{i}}+\left(p\left(Q_{j}\right)-c\right) \frac{\partial q_{i j}}{\partial m_{i}}-\frac{k^{\prime}\left(m_{i}\right)}{1-\tau_{i}} \\
& \beta_{12} \equiv q_{i i} p^{\prime}\left(Q_{i}\right) \frac{\partial Q_{i}}{\partial m_{j}}+\left(p\left(Q_{i}\right)-c\right) \frac{\partial q_{i i}}{\partial m_{j}}+q_{i j} p^{\prime}\left(Q_{j}\right) \frac{\partial Q_{j}}{\partial m_{j}}+\left(p\left(Q_{j}\right)-c\right) \frac{\partial q_{i j}}{\partial m_{j}} \\
& \beta_{21} \equiv q_{j i} p^{\prime}\left(Q_{i}\right) \frac{\partial Q_{i}}{\partial m_{i}}+\left(p\left(Q_{i}\right)-c\right) \frac{\partial q_{j i}}{\partial m_{i}}+q_{j j} p^{\prime}\left(Q_{j}\right) \frac{\partial Q_{j}}{\partial m_{i}}+\left(p\left(Q_{j}\right)-c\right) \frac{\partial q_{j j}}{\partial m_{i}} \\
& \beta_{22} \equiv q_{j i} p^{\prime}\left(Q_{i}\right) \frac{\partial Q_{i}}{\partial m_{j}}+\left(p\left(Q_{i}\right)-c\right) \frac{\partial q_{j i}}{\partial m_{j}}+q_{j j} p^{\prime}\left(Q_{j}\right) \frac{\partial Q_{j}}{\partial m_{j}}+\left(p\left(Q_{j}\right)-c\right) \frac{\partial q_{j j}}{\partial m_{j}}-\frac{k^{\prime}\left(m_{j}\right)}{1-\tau_{j}} .
\end{aligned}
$$


Differentiating the system (11), we obtain

$$
\begin{aligned}
\left(\begin{array}{c}
\partial m_{i} / \partial \tau_{i} \\
\partial m_{j} / \partial \tau_{i}
\end{array}\right) & =\frac{1}{\operatorname{det}(B)}\left(\begin{array}{cc}
\beta_{22} & -\beta_{12} \\
-\beta_{21} & \beta_{11}
\end{array}\right)\left(\begin{array}{c}
k^{\prime}\left(m_{i}\right) /\left(1-\tau_{i}\right)^{2} \\
0
\end{array}\right) \\
& =\frac{k^{\prime}\left(m_{i}\right)}{\operatorname{det}(B)\left(1-\tau_{i}\right)^{2}}\left(\begin{array}{c}
\beta_{22} \\
-\beta_{21}
\end{array}\right) .
\end{aligned}
$$

The determinant of $B$ is positive since

$$
\begin{aligned}
\operatorname{det}(B) & =-\frac{k^{\prime}\left(m_{i}\right)\left(1-\tau_{j}\right)+k^{\prime}\left(m_{j}\right)\left(1-\tau_{i}\right)}{n\left(1-\tau_{i}\right)\left(1-\tau_{j}\right)}\left[q_{i i} p^{\prime}\left(Q_{i}\right) \frac{\partial Q_{i}}{\partial m_{i}}+q_{j j} p^{\prime}\left(Q_{j}\right) \frac{\partial Q_{j}}{\partial m_{j}}\right. \\
& \left.+n\left(p\left(Q_{i}\right)-c\right) \frac{\partial q_{i i}}{\partial m_{i}}+n\left(p\left(Q_{j}\right)-c\right) \frac{\partial q_{j j}}{\partial m_{j}}\right]+\frac{k^{\prime}\left(m_{i}\right) k^{\prime}\left(m_{j}\right)}{\left(1-\tau_{i}\right)\left(1-\tau_{j}\right)}>0
\end{aligned}
$$

where the inequality comes from the assumptions on $p\left(Q_{i}\right)$ and $k\left(m_{i}\right)$, and (10). We also know that $\beta_{21}<0$ and $\beta_{22}<0$. Hence,

$$
\frac{\partial m_{i}}{\partial \tau_{i}}<0 \quad \text { and } \quad \frac{\partial m_{j}}{\partial \tau_{i}}>0
$$

Moreover, (10) implies that $\partial Q_{i} / \partial m_{i}=\partial Q_{i} / \partial m_{j}, \partial Q_{j} / \partial m_{i}=\partial Q_{j} / \partial m_{j}, \partial q_{i i} / \partial m_{i}=\partial q_{i i} / \partial m_{j}$, $\partial q_{j j} / \partial m_{i}=\partial q_{j j} / \partial m_{j}, \partial q_{i j} / \partial m_{i}=\partial q_{i j} / \partial m_{j}$ and $\partial q_{j i} / \partial m_{i}=\partial q_{j i} / \partial m_{j}$, which lead to $\beta_{22}<\beta_{21}<$ 0 and hence $-\partial m_{i} / \partial \tau_{i}>\partial m_{j} / \partial \tau_{i}>0$. Using these results, we have

$$
\left|\frac{\partial m_{i}}{\partial \tau_{i}}\right|>\left|\frac{\partial m_{j}}{\partial \tau_{i}}\right| .
$$

Appendix B: Proof of Proposition 2. 
Differentiate (8) and evaluate it at $\tau_{i}=\tau_{j}=0$ to obtain

$$
\begin{aligned}
\left.\frac{\partial W_{i}}{\partial \tau_{i}}\right|_{\tau_{i}=\tau_{j}=0} & =\left\{-Q_{i} p^{\prime}\left(Q_{i}\right) \frac{\partial Q_{i}}{\partial m_{i}}+m_{i}\left[q_{i i} p^{\prime}\left(Q_{i}\right) \frac{\partial Q_{i}}{\partial m_{i}}+\left(p\left(Q_{i}\right)-c\right) \frac{\partial q_{i i}}{\partial m_{i}}+q_{i j} p^{\prime}\left(Q_{j}\right) \frac{\partial Q_{j}}{\partial m_{i}}\right.\right. \\
& \left.\left.+\left(p\left(Q_{j}\right)-c\right) \frac{\partial q_{i j}}{\partial m_{i}}-k^{\prime}\left(m_{i}\right)\right]\right\} \frac{\partial m_{i}}{\partial \tau_{i}}+\left\{-Q_{i} p^{\prime}\left(Q_{i}\right) \frac{\partial Q_{i}}{\partial m_{j}}+m_{i}\left[q_{i i} p^{\prime}\left(Q_{i}\right) \frac{\partial Q_{i}}{\partial m_{j}}\right.\right. \\
& \left.\left.+\left(p\left(Q_{i}\right)-c\right) \frac{\partial q_{i i}}{\partial m_{j}}+q_{i j} p^{\prime}\left(Q_{j}\right) \frac{\partial Q_{j}}{\partial m_{j}}+\left(p\left(Q_{j}\right)-c\right) \frac{\partial q_{i j}}{\partial m_{j}}\right]\right\} \frac{\partial m_{j}}{\partial \tau_{i}} .
\end{aligned}
$$

By (9), $Q_{i}=Q_{j}$. This and (10), imply that $q_{i i}=q_{j j}=q_{i j}=q_{j i}, \partial Q_{j} / \partial m_{i}=\partial Q_{i} / \partial m_{i}$ and $\partial Q_{j} / \partial m_{j}=\partial Q_{i} / \partial m_{j}$. The free entry condition (11) at no tax $\left(\tau_{i}=\tau_{j}=0\right)$ implies $m_{i}=m_{j}$. Using these results, we obtain

$$
\begin{aligned}
\left.\frac{\partial W_{i}}{\partial \tau_{i}}\right|_{\tau_{i}=\tau_{j}=0} & =\left\{-Q_{i} p^{\prime}\left(Q_{i}\right) \frac{\partial Q_{i}}{\partial m_{i}}+m_{i} q_{i i} p^{\prime}\left(Q_{i}\right) \frac{\partial Q_{i}}{\partial m_{i}}+m_{j} q_{j i} p^{\prime}\left(Q_{i}\right) \frac{\partial Q_{i}}{\partial m_{i}}+m_{i}\left[\left(p\left(Q_{i}\right)-c\right) \frac{\partial q_{i i}}{\partial m_{i}}\right.\right. \\
& \left.\left.+\left(p\left(Q_{j}\right)-c\right) \frac{\partial q_{i j}}{\partial m_{i}}-k^{\prime}\left(m_{i}\right)\right]\right\} \frac{\partial m_{i}}{\partial \tau_{i}}+\left\{-Q_{i} p^{\prime}\left(Q_{i}\right) \frac{\partial Q_{i}}{\partial m_{j}}+m_{i} q_{i i} p^{\prime}\left(Q_{i}\right) \frac{\partial Q_{i}}{\partial m_{j}}\right. \\
& \left.+m_{j} q_{j i} p^{\prime}\left(Q_{i}\right) \frac{\partial Q_{i}}{\partial m_{j}}+m_{i}\left[\left(p\left(Q_{i}\right)-c\right) \frac{\partial q_{i i}}{\partial m_{j}}+\left(p\left(Q_{j}\right)-c\right) \frac{\partial q_{i j}}{\partial m_{j}}\right]\right\} \frac{\partial m_{j}}{\partial \tau_{i}} \\
& =m_{i}\left[\left(p\left(Q_{i}\right)-c\right) \frac{\partial q_{i i}}{\partial m_{i}}+\left(p\left(Q_{j}\right)-c\right) \frac{\partial q_{i j}}{\partial m_{i}}-k^{\prime}\left(m_{i}\right)\right] \frac{\partial m_{i}}{\partial \tau_{i}} \\
& +m_{i}\left[\left(p\left(Q_{i}\right)-c\right) \frac{\partial q_{i i}}{\partial m_{j}}+\left(p\left(Q_{j}\right)-c\right) \frac{\partial q_{i j}}{\partial m_{j}}\right] \frac{\partial m_{j}}{\partial \tau_{i}} .
\end{aligned}
$$

Proposition $1\left(-\partial m_{i} / \partial \tau_{i}>\partial m_{j} / \partial \tau_{i}>0\right)$ and the properties used in Appendix A $\left(\partial q_{i i} / \partial m_{i}=\right.$ $\partial q_{i i} / \partial m_{j}$ and $\left.\partial q_{i j} / \partial m_{i}=\partial q_{i j} / \partial m_{j}\right)$ imply

$$
\begin{aligned}
\left.\frac{\partial W_{i}}{\partial \tau_{i}}\right|_{\tau_{i}=\tau_{j}=0} & >m_{i}\left[\left(p\left(Q_{i}\right)-c\right) \frac{\partial q_{i i}}{\partial m_{i}}+\left(p\left(Q_{j}\right)-c\right) \frac{\partial q_{i j}}{\partial m_{i}}-k^{\prime}\left(m_{i}\right)\right] \frac{\partial m_{i}}{\partial \tau_{i}} \\
& +m_{i}\left[\left(p\left(Q_{i}\right)-c\right) \frac{\partial q_{i i}}{\partial m_{j}}+\left(p\left(Q_{j}\right)-c\right) \frac{\partial q_{i j}}{\partial m_{j}}\right]\left(-\frac{\partial m_{i}}{\partial \tau_{i}}\right) \\
& =-k^{\prime}\left(m_{i}\right) \frac{\partial m_{i}}{\partial \tau_{i}}>0 .
\end{aligned}
$$

\section{Appendix C: Proof of Proposition 3.}

Equations (9) and (10) imply that $Q_{i}=Q_{j}, q_{i i}=q_{j j}=q_{i j}=q_{j i}, m_{i}=m_{j}, \partial Q_{j} / \partial m_{i}=$ 
$\partial Q_{i} / \partial m_{i}, \partial Q_{j} / \partial m_{j}=\partial Q_{i} / \partial m_{j}, \partial Q_{i} / \partial m_{i}=\partial Q_{i} / \partial m_{j}, \partial Q_{j} / \partial m_{i}=\partial Q_{j} / \partial m_{j}, \partial q_{i i} / \partial m_{i}=$ $\partial q_{i i} / \partial m_{j}, \partial q_{j j} / \partial m_{i}=\partial q_{j j} / \partial m_{j}, \partial q_{i j} / \partial m_{i}=\partial q_{i j} / \partial m_{j}, \partial q_{j i} / \partial m_{i}=\partial q_{j i} / \partial m_{j}$, and $-\partial m_{i} / \partial \tau_{i}>$ $\partial m_{j} / \partial \tau_{i}>0\left(-\partial m_{j} / \partial \tau_{j}>\partial m_{i} / \partial \tau_{j}>0\right)$. When each government chooses the tax rate simultaneously, the first-order condition for country $j$ is given by

$$
\begin{aligned}
\frac{\partial W_{j}}{\partial \tau_{j}} & =\left\{-Q_{j} p^{\prime}\left(Q_{j}\right) \frac{\partial Q_{j}}{\partial m_{i}}+m_{j}\left[q_{j j} p^{\prime}\left(Q_{j}\right) \frac{\partial Q_{j}}{\partial m_{i}}+\left(p\left(Q_{j}\right)-c\right) \frac{\partial q_{j j}}{\partial m_{i}}+q_{j i} p^{\prime}\left(Q_{i}\right) \frac{\partial Q_{i}}{\partial m_{i}}\right.\right. \\
& \left.\left.+\left(p\left(Q_{i}\right)-c\right) \frac{\partial q_{j i}}{\partial m_{i}}\right]\right\} \frac{\partial m_{i}}{\partial \tau_{j}}+\left\{-Q_{j} p^{\prime}\left(Q_{j}\right) \frac{\partial Q_{j}}{\partial m_{j}}+\left(p\left(Q_{j}\right)-c\right) q_{j j}+\left(p\left(Q_{i}\right)-c\right) q_{j i}-k\left(m_{j}\right)\right. \\
& \left.+m_{j}\left[q_{j j} p^{\prime}\left(Q_{j}\right) \frac{\partial Q_{j}}{\partial m_{j}}+\left(p\left(Q_{j}\right)-c\right) \frac{\partial q_{j j}}{\partial m_{j}}+q_{j i} p^{\prime}\left(Q_{i}\right) \frac{\partial Q_{i}}{\partial m_{j}}+\left(p\left(Q_{i}\right)-c\right) \frac{\partial q_{j i}}{\partial m_{j}}-k^{\prime}\left(m_{j}\right)\right]\right\} \frac{\partial m_{j}}{\partial \tau_{j}} \\
& =0 .
\end{aligned}
$$

Using the properties given at the top of this appendix, we obtain

$$
\begin{aligned}
0 & =\frac{\partial W_{j}}{\partial \tau_{j}} \\
& =m_{j}\left[\left(p\left(Q_{j}\right)-c\right) \frac{\partial q_{j j}}{\partial m_{i}}+\left(p\left(Q_{i}\right)-c\right) \frac{\partial q_{j i}}{\partial m_{i}}\right] \frac{\partial m_{i}}{\partial \tau_{j}} \\
& +\left\{\left(p\left(Q_{j}\right)-c\right) q_{j j}+\left(p\left(Q_{i}\right)-c\right) q_{j i}-k\left(m_{j}\right)+m_{j}\left[\left(p\left(Q_{j}\right)-c\right) \frac{\partial q_{j j}}{\partial m_{j}}+\left(p\left(Q_{i}\right)-c\right) \frac{\partial q_{j i}}{\partial m_{j}}-k^{\prime}\left(m_{j}\right)\right]\right\} \frac{\partial m_{j}}{\partial \tau_{j}} \\
& >m_{j}\left[\left(p\left(Q_{j}\right)-c\right) \frac{\partial q_{j j}}{\partial m_{i}}+\left(p\left(Q_{i}\right)-c\right) \frac{\partial q_{j i}}{\partial m_{i}}\right]\left(-\frac{\partial m_{j}}{\partial \tau_{j}}\right) \\
& +\left\{\left(p\left(Q_{j}\right)-c\right) q_{j j}+\left(p\left(Q_{i}\right)-c\right) q_{j i}-k\left(m_{j}\right)+m_{j}\left[\left(p\left(Q_{j}\right)-c\right) \frac{\partial q_{j j}}{\partial m_{j}}+\left(p\left(Q_{i}\right)-c\right) \frac{\partial q_{j i}}{\partial m_{j}}-k^{\prime}\left(m_{j}\right)\right]\right\} \frac{\partial m_{j}}{\partial \tau_{j}}
\end{aligned}
$$

which simplifies to

$$
0>\left[\left(p\left(Q_{j}\right)-c\right) q_{j j}+\left(p\left(Q_{i}\right)-c\right) q_{j i}-k\left(m_{j}\right)-m_{j} k^{\prime}\left(m_{j}\right)\right] \frac{\partial m_{j}}{\partial \tau_{j}} .
$$

Because $\partial m_{j} / \partial \tau_{j}<0$, we now have that

$$
0<\left(p\left(Q_{j}\right)-c\right) q_{j j}+\left(p\left(Q_{i}\right)-c\right) q_{j i}-k\left(m_{j}\right)-m_{j} k^{\prime}\left(m_{j}\right) .
$$


In a symmetric equilibrium,

$$
\begin{aligned}
& \left.\frac{\partial W_{j}}{\partial \tau_{i}}\right|_{\text {symmetric equilibrium }} \\
& =\left\{-Q_{j} p^{\prime}\left(Q_{j}\right) \frac{\partial Q_{j}}{\partial m_{i}}+m_{j}\left[q_{j j} p^{\prime}\left(Q_{j}\right) \frac{\partial Q_{j}}{\partial m_{i}}+\left(p\left(Q_{j}\right)-c\right) \frac{\partial q_{j j}}{\partial m_{i}}+q_{j i} p^{\prime}\left(Q_{i}\right) \frac{\partial Q_{i}}{\partial m_{i}}\right.\right. \\
& \left.\left.+\left(p\left(Q_{i}\right)-c\right) \frac{\partial q_{j i}}{\partial m_{i}}\right]\right\} \frac{\partial m_{i}}{\partial \tau_{i}}+\left\{-Q_{j} p^{\prime}\left(Q_{j}\right) \frac{\partial Q_{j}}{\partial m_{j}}+\left(p\left(Q_{j}\right)-c\right) q_{j j}+\left(p\left(Q_{i}\right)-c\right) q_{j i}-k\left(m_{j}\right)\right. \\
& \left.+m_{j}\left[q_{j j} p^{\prime}\left(Q_{j}\right) \frac{\partial Q_{j}}{\partial m_{j}}+\left(p\left(Q_{j}\right)-c\right) \frac{\partial q_{j j}}{\partial m_{j}}+q_{j i} p^{\prime}\left(Q_{i}\right) \frac{\partial Q_{i}}{\partial m_{j}}+\left(p\left(Q_{i}\right)-c\right) \frac{\partial q_{j i}}{\partial m_{j}}-k^{\prime}\left(m_{j}\right)\right]\right\} \frac{\partial m_{j}}{\partial \tau_{i}} .
\end{aligned}
$$

Use the properties of symmetry to simplify the above as

$$
\begin{aligned}
& \left.\frac{\partial W_{j}}{\partial \tau_{i}}\right|_{\text {symmetric equilibrium }} \\
& >m_{j}\left[\left(p\left(Q_{j}\right)-c\right) \frac{\partial q_{j j}}{\partial m_{i}}+\left(p\left(Q_{i}\right)-c\right) \frac{\partial q_{j i}}{\partial m_{i}}\right] \frac{\partial m_{i}}{\partial \tau_{i}} \\
& +m_{j}\left[\left(p\left(Q_{j}\right)-c\right) \frac{\partial q_{j j}}{\partial m_{j}}+\left(p\left(Q_{i}\right)-c\right) \frac{\partial q_{j i}}{\partial m_{j}}\right]\left(-\frac{\partial m_{i}}{\partial \tau_{i}}\right) \\
& +\left[\left(p\left(Q_{j}\right)-c\right) q_{j j}+\left(p\left(Q_{i}\right)-c\right) q_{j i}-k\left(m_{j}\right)-m_{j} k^{\prime}\left(m_{j}\right)\right] \frac{\partial m_{j}}{\partial \tau_{i}} \\
& =\left[\left(p\left(Q_{j}\right)-c\right) q_{j j}+\left(p\left(Q_{i}\right)-c\right) q_{j i}-k\left(m_{j}\right)-m_{j} k^{\prime}\left(m_{j}\right)\right] \frac{\partial m_{j}}{\partial \tau_{i}} \\
& >0 .
\end{aligned}
$$

The last inequality comes from $(\mathrm{C} 1)$ and $\partial m_{j} / \partial \tau_{i}>0$.

\section{Appendix D: Proof of Proposition 4.}

We use (14) to derive the effect of corporate tax on the number of firms. Define $\Phi$ and $\Psi_{i}$ by

$$
\begin{aligned}
\Phi & \equiv\left(\begin{array}{cc}
\partial \phi_{w} / \partial m_{w}-k /\left[2\left(1-\tau_{w}\right)\right] & \partial \phi_{w} / \partial m_{e} \\
\partial \phi_{e} / \partial m_{w} & \partial \phi_{e} / \partial m_{e}-k /\left[2\left(1-\tau_{e}\right)\right]
\end{array}\right) \\
& =\left(\begin{array}{cc}
-2 \phi_{w} /(1+M)-k /\left[2\left(1-\tau_{w}\right)\right] & -2 \phi_{w} /(1+M)+\Psi_{e} \\
-2 \phi_{e} /(1+M)+\Psi_{w} & -2 \phi_{e} /(1+M)-k /\left[2\left(1-\tau_{e}\right)\right]
\end{array}\right)
\end{aligned}
$$


and

$$
\Psi_{i} \equiv \frac{2 n t^{2}\left(1+2 m_{i}\right)}{(1+M)^{2}}
$$

From these expressions, we obtain

$$
\left(\begin{array}{c}
\partial m_{i} / \partial \tau_{i} \\
\partial m_{j} / \partial \tau_{i}
\end{array}\right)=\frac{k m_{i}}{2 \operatorname{det}(\Phi)\left(1-\tau_{i}\right)^{2}}\left(\begin{array}{c}
-2 \phi_{j} /(1+M)-k /\left[2\left(1-\tau_{j}\right)\right] \\
2 \phi_{j} /(1+M)-\Psi_{i}
\end{array}\right)
$$

In the first stage, each government chooses the tax rate, taking the other government's tax rate as given and anticipating the responses of firms (described in (D1)). Maximization of national welfare

$$
W_{i}=\frac{n}{2}\left(\frac{M-t m_{j}}{1+M}\right)^{2}+m_{i}\left\{n\left(\frac{1+t m_{j}}{1+M}\right)^{2}+n\left[\frac{1-t\left(1+m_{j}\right)}{1+M}\right]^{2}-\frac{k m_{i}}{2}\right\} .
$$

gives the first-order condition for country $i$ :

$$
0=\frac{\partial W_{i}}{\partial \tau_{i}}=\left[-\frac{2 \xi_{i 1}}{(1+M)^{3}}+\frac{\xi_{i 2}}{(1+M)^{2}}-k m_{i}\right] \frac{\partial m_{i}}{\partial \tau_{i}}+\left[-\frac{2 \xi_{i 1}}{(1+M)^{3}}+\frac{\xi_{i 3}}{(1+M)^{2}}\right] \frac{\partial m_{j}}{\partial \tau_{i}} .
$$

where

$$
\begin{aligned}
\xi_{i 1} & \equiv n\left\{\frac{\left(M-t m_{j}\right)^{2}}{2}+m_{i}\left(1+t m_{j}\right)^{2}+m_{i}\left[1-t\left(1+m_{j}\right)\right]^{2}\right\} \\
\xi_{i 2} & \equiv n\left\{M-t m_{j}+\left(1+t m_{j}\right)^{2}+\left[1-t\left(1+m_{j}\right)\right]^{2}\right\} \\
\xi_{i 3} & \equiv n\left[(1-t)\left(M-t m_{j}\right)+2 t^{2} m_{i}\left(1+2 m_{j}\right)\right] .
\end{aligned}
$$

Equation (D3) simplifies to

$$
\left[-\frac{2 \xi_{i 1}}{(1+M)^{3}}+\frac{\xi_{i 2}}{(1+M)^{2}}-k m_{i}\right]\left(\frac{2 \phi_{j}}{1+M}+\frac{k}{2\left(1-\tau_{j}\right)}\right)=\left[-\frac{2 \xi_{i 1}}{(1+M)^{3}}+\frac{\xi_{i 3}}{(1+M)^{2}}\right]\left(\frac{2 \phi_{j}}{1+M}-\Psi_{i}\right) .
$$

Note that $\tau_{e}=\tau_{w}=0$ leads to the symmetric number of firms $m_{w}=m_{e}=M / 2$. 
Now, evaluating $\partial W_{i} / \partial \tau_{i}$ at $\tau_{w}=\tau_{e}=0$, we obtain

$$
\operatorname{sgn}\left[\left.\frac{\partial W_{w}}{\partial \tau_{w}}\right|_{\tau_{w}=\tau_{e}=0}\right]=\operatorname{sgn}[\Xi]
$$

where

$$
\Xi \equiv k(1+M)^{2}(1+3 M)+n\left\{M(7+4 M)\left[t-\frac{3 M-1}{M(7+4 M)}\right]^{2}-\frac{25 M^{2}+22 M+1}{M(7+4 M)}\right\} .
$$

A calculation yields

$$
\begin{aligned}
\Xi & \geq k(1+M)^{2}(1+3 M)-\frac{n\left(25 M^{2}+22 M+1\right)}{M(7+4 M)} \\
& >\frac{4 n(1+3 M)}{M}-\frac{n\left(25 M^{2}+22 M+1\right)}{M(7+4 M)} \\
& =\frac{n\left(23 M^{2}+78 M+27\right)}{M(7+4 M)} \\
& >0 .
\end{aligned}
$$

The second inequality comes from $k(1+M)^{2}>4 n / M$ using the first-order condition (14). ${ }^{12}$ From (D5), we have

$$
\left.\frac{\partial W_{w}}{\partial \tau_{w}}\right|_{\tau_{w}=\tau_{e}=0}>0
$$

Appendix E: The existence and uniqueness of symmetric Nash equilibrium of the tax game.

Assume no trade cost. Taking the limit of $t \rightarrow 0$ yield $\Psi_{i}=0, \xi_{i 1}=n M^{2} / 2+N m_{i}, \xi_{i 2}=n M+N$ and $\xi_{i 3}=n M$. Then, by (14), (D4) can be written as

$$
\left[-\frac{2 \xi_{i 1}}{(1+M)^{3}}+\frac{\xi_{i 2}}{(1+M)^{2}}-k m_{i}\right]\left(\frac{1}{2}+\frac{m_{j}}{1+M}\right)=\left[-\frac{2 \xi_{i 1}}{(1+M)^{3}}+\frac{\xi_{i 3}}{(1+M)^{2}}\right] \frac{m_{j}}{1+M}
$$

which simplifies to

$$
\frac{N\left(1+3 m_{j}-m_{i}\right)+n M}{(1+M)^{3}}=k m_{i}\left(1+\frac{2 m_{j}}{1+M}\right) .
$$

\footnotetext{
${ }^{12}$ Summing up the zero profit conditions for two countries after substituting $\tau_{w}=\tau_{e}=0$, we obtain that $k M / 2=\phi_{w}+\phi_{e}>2 n /(1+M)^{2}$.
} 
First, we show that the first order condition $(\mathrm{E} 1)$ determines $\left(\tau_{w}^{o}, \tau_{e}^{o}\right)$ uniquely. Subtracting $(\mathrm{E} 1)$ of West from that of East, we obtain

$$
\left[\frac{4 N}{(1+M)^{3}}+k\right]\left(m_{w}-m_{e}\right)=0 \text {. }
$$

Because the bracketed term is positive, $m_{w}^{o}=m_{e}^{o}=M / 2$. Substituting $m_{e}=m_{w}$ into (E1), we obtain

$$
k=\frac{N\left(1+3 m_{w}\right)}{m_{w}\left(1+2 m_{w}\right)^{2}\left(1+4 m_{w}\right)} .
$$

The right hand side of (E2) is decreasing in $m_{w}$. Hence, given $k<4 N / 45$, it has the unique solution for $m_{w}>0$, which determines $\left(m_{w}^{o}, m_{e}^{o}\right)$ uniquely. Substituting $t=0$ into (14), and using the fact that $\left(m_{w}^{o}, m_{e}^{o}\right)$ is unique and $m_{e}=m_{w}$, we can determine $\left(\tau_{w}^{o}, \tau_{e}^{o}\right)$ uniquely and $\tau_{w}^{o}=\tau_{e}^{o}$.

Next, we show that $\left.W_{w}\right|_{\tau_{e}=\tau_{e}^{o}}$ is quasi-concave in $\tau_{w}$. The second derivative of $\left.W_{w}\right|_{\tau_{e}=\tau_{e}^{o}}$ with respect to $\tau_{w}$ at $\left(\tau_{w}^{o}, \tau_{e}^{o}\right)$ (and hence at $\left.\left(m_{w}^{o}, m_{e}^{o}\right)\right)$ is given by

$$
\frac{d^{2}}{d \tau_{w}^{2}}\left(\left.W_{w}\right|_{\tau_{e}=\tau_{e}^{o}}\right)=-\frac{k^{2} M(1+M)^{2}\left[4 k^{2} M(1+M)^{5}+\sigma_{1}+\sigma_{2}+\sigma_{3}\right]}{8\left(1-\tau_{w}^{o}\right)\left[k(1+M)^{3}+8 N\left(1-\tau_{w}^{o}\right)\right]^{3}}
$$

where

$$
\begin{aligned}
& \sigma_{1} \equiv k^{2} M^{2}(1+M)^{5}(16+13 M), \\
& \sigma_{2} \equiv-8 N^{2}\left(1-\tau_{w}^{o}\right)(4+M)(1+3 M), \\
& \sigma_{3} \equiv k N(1+M)^{2}\left\{-4+M\left(21-32 \tau_{w}^{o}\right)+M^{2}\left[151+158 M-152 \tau_{w}^{o}(1+M)\right]\right\} .
\end{aligned}
$$

Here, use has been made of the fact that $m_{w}^{o}=m_{e}^{o}=M / 2$. This fact allows the free entry condition (14) and the first order condition (E1) to be rewritten

$$
\begin{aligned}
4 N\left(1-\tau_{w}^{o}\right) & =k M(1+M)^{2}, \\
k M(1+M)^{2}(1+2 M) & =2 N\left(1+\frac{3 M}{2}\right) .
\end{aligned}
$$


Substituting these into $\sigma_{1}$ and $\sigma_{2}$ yields

$$
\begin{aligned}
\sigma_{1} & =\frac{2 N k M(1+M)^{3}(16+13 M)(1+3 M / 2)}{1+2 M} \\
\sigma_{2} & =-2 N k M(1+M)^{2}(4+M)(1+3 M) .
\end{aligned}
$$

Hence,

$$
\sigma_{1}+\sigma_{2}=\frac{2 N k M(1+M)^{2}\{24+M[64+M(55+27 M)]\}}{2+4 M}>0
$$

Moreover, since $m_{w}^{o}=m_{e}^{o}>1$, the total number of firms $M$ is larger than 2. Hence,

$$
\begin{aligned}
\sigma_{3} & >k N(1+M)^{2}\left[-4+M\left(21-32 \tau_{w}^{o}\right)+M^{2}(6 M-1)\right] \\
& >k N(1+M)^{2}\left[-4+M\left(21-32 \tau_{w}^{o}+11 M\right)\right] \\
& >k N(1+M)^{2}[-4+11 M(M-1)] \\
& >k N(1+M)^{2}(11 M-4)>0 .
\end{aligned}
$$

From (E3), (E4) and (E5), we have that

$$
\frac{d^{2}}{d \tau_{w}^{2}}\left(\left.W_{w}\right|_{\tau_{e}=\tau_{e}^{o}}\right)<0
$$

Because there exists the unique $\tau_{w}^{o}$ that satisfies the first order condition $d W_{w} / d \tau_{w}=0$ for $\tau_{e}^{o}$, $W_{w}\left(\tau_{w}, \tau_{e}^{o}\right)$ is quasi-concave in $\tau_{w}$. Similar arguments hold for East.

Next, we check the behavior of $d W_{w} / d \tau_{w}$ when $\tau_{w} \rightarrow 1$ or $\tau_{w} \rightarrow-\infty$. For $\tau_{e}^{o}$ given, it follows from (14) that $\lim _{\tau_{w} \rightarrow 1} m_{w}=0$, $\lim _{\tau_{w} \rightarrow-\infty} m_{w}=+\infty, \lim _{\tau_{w} \rightarrow 1} m_{e}=\widehat{m}<+\infty$ and $\lim _{\tau_{w} \rightarrow-\infty} m_{e}=0$ where $\widehat{m}$ is determined by

$$
2 N\left(1-\tau_{e}^{o}\right)=m(1+m)^{2}
$$


Using (14), $d W_{w} /\left.d \tau_{w}\right|_{\tau_{e}=\tau_{e}^{o}}$ can be rearranged to yield

$$
\begin{aligned}
\left.\frac{d W_{w}}{d \tau_{w}}\right|_{\tau_{e}=\tau_{e}^{o}} & =\frac{k N}{\left(1-\tau_{e}^{o}\right)}\left[-\frac{N\left(1+3 m_{e}-m_{w}\right)+n M}{(1+M)^{3}}+k m_{w}\left(1+\frac{2 m_{e}}{1+M}\right)\right] \\
& \times\left[\frac{2 N}{1+M}+\frac{1+M}{1-\tau_{e}^{o}}\left(m_{w}+\frac{k(1+M)}{2}\right)\right]^{-1} .
\end{aligned}
$$

From this, we obtain

$$
\begin{aligned}
\left.\lim _{\tau_{w} \rightarrow 1} \frac{d W_{w}}{d \tau_{w}}\right|_{\tau_{e}=\tau_{e}^{o}} & =\left.\lim _{\left(m_{w}, m_{e}\right) \rightarrow(0, \widehat{m})} \frac{d W_{w}}{d \tau_{w}}\right|_{\tau_{e}=\tau_{e}^{o}} \\
& =-\frac{k N^{2}(2+7 \widehat{m})}{(1+\widehat{m})^{2}\left[k(1+\widehat{m})^{3}+4 N\left(1-\tau_{e}^{o}\right)\right]}<0 .
\end{aligned}
$$

and

$$
\left.\lim _{\tau_{w} \rightarrow-\infty} \frac{d W_{w}}{d \tau_{w}}\right|_{\tau_{e}=\tau_{e}^{o}}=\left.\lim _{\left(m_{w}, m_{e}\right) \rightarrow(+\infty, 0)} \frac{d W_{w}}{d \tau_{w}}\right|_{\tau_{e}=\tau_{e}^{o}}=0 .
$$

These two conditions and quasi-concavity of $W_{w}\left(\tau_{w}, \tau_{e}^{o}\right)$ imply that $W_{w}\left(\tau_{w}, \tau_{e}^{o}\right)$ is maximized at $\tau_{w}^{o}$. In other words, $\left(\tau_{w}^{o}, \tau_{e}^{o}\right)$ is a Nash equilibrium of the tax game.

It remains to consider the cases of corner solutions in which one country has no firms $\left(m_{i}=0\right)$. Two cases can arise. In one, a country sets a tax rate so high that it loses all firms. Clearly, such a strategy is never optimal for this country. In the other, a country gives such a high subsidy that it gets all firms. Again, this cannot happen in equilibrium because the other government would reduce its tax rate. Thus, $\left(\tau_{w}^{o}, \tau_{e}^{o}\right)$ is the unique Nash equilibrium of the tax game.

\section{Appendix F: Autarky with linear functions.}

In this appendix, we characterize the equilibrium allocation under autarky. Cournot competition leads to the output and price levels of

$$
q=\frac{n}{1+m}, \quad Q=\frac{m n}{1+m}, \quad p=\frac{1}{1+m}
$$


The profit (2) of a firm then becomes as

$$
\pi=n(1-\tau)\left(\frac{1}{1+m}\right)^{2}-\frac{k m}{2}
$$

The zero profit condition $\pi=0$ in the second stage determines the number of firms for a given corporate tax:

$$
k=\frac{2 n(1-\tau)}{m(1+m)^{2}} .
$$

In the first stage, each government maximizes the welfare function (12) with respect to $\tau$ subject to the balanced-budget constraint $s n=m n \tau /(1+m)^{2}$. By $(\mathrm{F} 2)$, corporate taxation reduces the number of firms $(\partial m / \partial \tau<0)$. Substituting $(\mathrm{F} 1)$ and $s n=m n \tau /(1+m)^{2}$ into $(12)$, we obtain

$$
W=m\left[\frac{n}{(1+m)^{2}}\left(1+\frac{m}{2}\right)-\frac{k m}{2}\right] .
$$

By $(\mathrm{F} 2)$, the number of firms $m$ is a function of tax rate $\tau$, which makes welfare in (F3) a function of $\tau$. Taking $\partial m / \partial \tau<0$ into consideration, the first-order condition of welfare maximization yields

$$
\tau^{a}=1-\frac{1}{2\left(1+m^{a}\right)}
$$

where $m^{a}$ is determined by

$$
k=\frac{n}{m^{a}\left(1+m^{a}\right)^{3}} .
$$

Since there are more than one firm in the equilibrium, (F4) implies that $n \geq k$ (i.e., $N \geq 2 k$ ), which in turn implies that the equilibrium tax rate is positive $\left(\tau^{a}>0\right)$. It is straightforward that this allocation is optimal.

\section{Appendix G: Proof of Proposition 5.}

Calculations show that $m_{i} \geq 1$ in the closed economy (resp. in the open economy) if and only if $N \geq \lambda^{a} k$ (resp. $\left.N \geq \lambda^{o} k\right)$ where $\lambda^{a} \approx 16$ (resp. $\left.\lambda^{o} \approx 11.25\right)$. Therefore, we focus on the interval $N / k \in[16,+\infty)$ so that the number of firms is larger than one in both economies. 
Equations (F3) and (D2) are rearranged as

$$
W_{i}^{a}=\frac{N m^{a}\left(2+m^{a}\right)}{4\left(1+m^{a}\right)^{2}}-\frac{k\left(m^{a}\right)^{2}}{2}
$$

and

$$
W_{i}^{o}=\frac{N m^{o}\left(1+m^{o}\right)}{\left(1+2 m^{o}\right)^{2}}-\frac{k\left(m^{o}\right)^{2}}{2} .
$$

In the followings, we show (A) that $W_{i}^{o}>W_{i}^{a}$ when $N$ is small and is equal to $16 k$, but (B) that the result is reversed when $N$ goes to infinity.

When $N$ is equal to $16 k,(\mathrm{E} 2)$ and $(\mathrm{F} 4)$ yield $m^{a}=1$ and $m^{o} \approx 1.1571$, respectively. These numbers of firms lead to that

$$
\frac{W_{i}^{o}}{W_{i}^{a}} \approx 1.186
$$

which shows claim A above.

As for claim B, we first show how $m^{a}$ and $m^{o}$ diverge when $N$ goes to infinity. Define $\delta^{a}$ and $\delta^{o}$ as

$$
\begin{aligned}
\delta^{a} & \equiv \frac{1}{2 m(1+m)^{3}} \\
\delta^{o} & \equiv \frac{1+3 m}{m(1+2 m)^{2}(1+4 m)} .
\end{aligned}
$$

Then, (E2) and (F4) are represented as $k / N=\delta^{a}$ and $k / N=\delta^{o}$, respectively. Noting that both $\delta^{a}$ and $\delta^{o}$ are decreasing in $m$ and that, $\delta^{o}-\delta^{a}=\left\{1+4 m+2 m^{2}[2+m(2+3 m)]\right\} /\left[2 m(1+m)^{3}(1+\right.$ $\left.2 m)^{2}(1+4 m)\right]>0$ for all $m>0$, we readily know that

$$
m^{o}>m^{a} .
$$

Let $\bar{m}^{a}$ be the solution of $k / N=1 /\left(2 m^{4}\right)$ (i.e., $\left.\bar{m}^{a}=[N /(2 k)]^{1 / 4}\right)$. From the fact that $\delta^{a}-$ $1 /\left(2 m^{4}\right)=\left[m^{3}-(1+m)^{3}\right] /\left[2 m^{4}(1+m)^{3}\right]<0$ for all $m>0$, we obtain.

$$
m^{a}<\bar{m}^{a}
$$


Let $\underline{m}^{o}$ be the solution of $k / N=1 /(1+4 m)^{3}$ (i.e., $\left.\underline{m}^{o}=(1 / 4)\left[(N / k)^{1 / 3}-1\right]\right)$. Because $\delta^{o}-1 /(1+$ $4 m)^{3}=\{1+2 m[5+2 m(9+11 m)]\} /\left[m(1+2 m)^{2}(1+4 m)^{3}\right]>0$ for all $m>0$, we know that

$$
m^{o}>\underline{m}^{o} .
$$

Next form this ratio

$$
\frac{\underline{m}^{o}}{\bar{m}^{a}}=\frac{2^{1 / 4}}{4}\left[\left(\frac{N}{k}\right)^{1 / 12}-\left(\frac{k}{N}\right)^{1 / 4}\right]
$$

and note that

$$
\lim _{N \rightarrow+\infty} \frac{\underline{m}^{o}}{\overline{\bar{m}}^{a}}=+\infty .
$$

(G3) and (G4) imply that $m^{o} / m^{a}>\underline{m}^{o} / \bar{m}^{a}$. This and (G5) lead to

$$
\lim _{N \rightarrow+\infty} \frac{m^{o}}{m^{a}}=+\infty
$$

Now rearrange (G1) and (G2) as

$$
\begin{aligned}
\frac{W_{i}^{a}}{k} & =\left(\frac{N}{k}\right) \frac{m^{a}\left(2+m^{a}\right)}{4\left(1+m^{a}\right)^{2}}-\frac{\left(m^{a}\right)^{2}}{2} \\
\frac{W_{i}^{o}}{k} & =\left(\frac{N}{k}\right) \frac{m^{o}\left(1+m^{o}\right)}{\left(1+2 m^{o}\right)^{2}}-\frac{\left(m^{o}\right)^{2}}{2},
\end{aligned}
$$

and define the following functions of $m$.

$$
\begin{aligned}
\omega^{a}(m) & \equiv\left(\frac{N}{k}\right) \frac{m(2+m)}{4(1+m)^{2}}-\frac{m^{2}}{2} \\
\omega^{o}(m) & \equiv\left(\frac{N}{k}\right) \frac{m(1+m)}{(1+2 m)^{2}}-\frac{m^{2}}{2} .
\end{aligned}
$$

For a given $N / k$, a change in the number of firms leads to changes in $\omega(m)$ as

$$
\begin{aligned}
\omega^{a^{\prime}}(m) & =\frac{N / k+2 m-6 m^{2}-6 m^{3}-2 m^{4}}{2(1+m)^{3}} \\
\omega^{o^{\prime}}(m) & =\frac{N / k-m-6 m^{2}-12 m^{3}-8 m^{4}}{(1+2 m)^{3}} .
\end{aligned}
$$


Moreover, the second derivatives are given as

$$
\begin{aligned}
& \omega^{a^{\prime \prime}}(m)=-\frac{3 N / k+2+8 m+12 m^{2}+8 m^{3}+2 m^{4}}{2(1+m)^{4}}<0 \\
& \omega^{o^{\prime \prime}}(m)=-\frac{6 N / k+1+8 m+24 m^{2}+32 m^{3}+16 m^{4}}{(1+2 m)^{4}}<0 .
\end{aligned}
$$

Evaluating the first derivative at equilibrium values of $m$, we obtain

$$
\omega^{a^{\prime}}\left(m^{a}\right)=0
$$

Define $\Omega^{a}$ as

$$
\Omega^{a} \equiv\left(\frac{N}{k}\right) \frac{\bar{m}^{a}\left(2+\bar{m}^{a}\right)}{4\left(1+\bar{m}^{a}\right)^{2}}-\frac{\left(\bar{m}^{a}\right)^{2}}{2} .
$$

Then, equations (G3), (G7) and (G8) imply that

$$
\frac{W_{i}^{a}}{k}-\Omega^{a}=\omega^{a}\left(m^{a}\right)-\Omega^{a}>0 .
$$

We also obtain

$$
\begin{aligned}
\omega^{o^{\prime}}\left(m^{o}\right) & =-\frac{\left(m^{o}\right)^{2}\left(1+6 m^{o}\right)}{1+5 m^{o}+6\left(m^{o}\right)^{2}}<0 \\
\omega^{o^{\prime}}\left(\bar{m}^{a}\right) & =\frac{1+11 \bar{m}^{a}+42\left(\bar{m}^{a}\right)^{2}+52\left(\bar{m}^{a}\right)^{3}-8\left(\bar{m}^{a}\right)^{4}}{\left(1+2 \bar{m}^{a}\right)^{3}}
\end{aligned}
$$

$<0$ for a sufficiently large $\bar{m}^{a}$.

Define $\Omega^{\circ}$ as

$$
\Omega^{0} \equiv\left(\frac{N}{k}\right) \frac{\underline{m}^{o}\left(1+\underline{m}^{o}\right)}{\left(1+2 \underline{m}^{o}\right)^{2}}-\frac{\left(\underline{m}^{o}\right)^{2}}{2} .
$$

Note that $\lim _{N \rightarrow+\infty} \bar{m}^{a}=+\infty$. Then, equations (G4), (G5), (G7) and (G10) yield

$$
\frac{W_{i}^{o}}{k}-\Omega^{o}=\omega^{o}\left(m^{o}\right)-\Omega^{o}<0
$$


for a sufficiently large $N$. Equations (G9) and (G11) imply that

$$
\frac{W_{i}^{o}}{k}-\frac{W_{i}^{a}}{k}<\Omega^{o}-\Omega^{a} \text { for a sufficiently large } N
$$

Substituting $\bar{m}^{a}=[N /(2 k)]^{1 / 4}$ and $\underline{m}^{o}=(1 / 4)\left[(N / k)^{1 / 3}-1\right]$ into $\Omega^{o}-\Omega^{a}$, we obtain

$$
\begin{aligned}
\Omega^{o}-\Omega^{a} & =\frac{1}{32}\left\{-\left[\left(\frac{N}{k}\right)^{1 / 3}-1\right]^{2}+8 \sqrt{\frac{2 N}{k}}+\frac{8(N / k)\left[(N / k)^{1 / 3}-1\right]\left[(N / k)^{1 / 3}+3\right]}{\left[(N / k)^{1 / 3}+1\right]^{2}}\right. \\
& \left.-\frac{82^{3 / 4}(N / k)^{5 / 4}\left[2^{3 / 4}(N / k)^{1 / 4}+4\right]}{\left[2^{3 / 4}(N / k)^{1 / 4}+2\right]^{2}}\right\} .
\end{aligned}
$$

A calculation show that

$$
\lim _{N \rightarrow+\infty}\left(\Omega^{o}-\Omega^{a}\right)=-\infty
$$

Then (G12) implies that

$$
\lim _{N \rightarrow+\infty}\left(\frac{W_{i}^{o}}{k}-\frac{W_{i}^{a}}{k}\right)=-\infty
$$

and hence

$$
\lim _{N \rightarrow+\infty}\left(W_{i}^{o}-W_{i}^{a}\right)=-\infty
$$

\section{References}

[1] Andersson, F. and R. Forslid, 2003, Tax competition and economic geography, Journal of Public Economic Theory 5, 279-303.

[2] Baldwin, R., R. Forslid, P. Martin, G.I.P. Ottaviano and F. Robert-Nicoud, 2003, Economic Geography and Public Policy, Princeton University Press.

[3] Baldwin, R.E. and P. Krugman, 2004, Agglomeration, integration and tax harmonization, European Economic Review 48, 1-23. 
[4] Borck, R. and M. Pflüer, 2006, Agglomeration and tax competition, European Economic Review 50, 647-668.

[5] Brander, J. A., and P. Krugman, 1983, A 'reciprocal dumping' model of international trade, Journal of International Economics 15, 313-321.

[6] Brander, J. A., and B. J. Spencer, 1985, Export subsidies and international market share rivalry, Journal of International Economics 18, 83-100.

[7] Bucovetsky, S., 1991, Asymmetric tax competition, Journal of Urban Economics 30, 167-181.

[8] Devereux, M. P., R. Griffith and A. Klemm, 2002 Corporate income tax reforms and international tax competition, Economic Policy 35,451-495.

[9] Fujita, M., P. Krugman, and A.J. Venables, 1999, The Spatial Economy: Cities, Regions, and International Trade, Cambridge, Mass.: MIT Press.

[10] Haufler, A and M. Pflüer, 2004, International commodity taxation under monopolistic competition, Journal of Public Economic Theory 6, 445-470.

[11] Haufler, A. and I. Wooton, 2010, Competition for firms in an oligopolistic industry: The impact of economic integration, Journal of International Economics 80, 239-248.

[12] Head, K., T. Mayer, and J. Ries, 2002, On the pervasiveness of home market effects, Economica 69, 371-390.

[13] Helpman, E., M. J. Melitz, and S. R. Yeaple, 2004, Export versus FDI with heterogeneous firms, American Economic Review 94, 300-316.

[14] Kind, H.J., K.H.M. Knarvik, and G. Schjelderup, 2000, Competing for capital in a lumpy world, Journal of Public Economics 78, 253-274.

[15] Krugman, P., 1980, Scale economies, product differentiation, and the pattern of trade, American Economic Review 70, 950-959. 
[16] Ludema, R.D. and I. Wooton, 2000, Economic geography and the fiscal effects of integration, Journal of International Economics 52, 331-357.

[17] Mankiw, G.N. and M.D. Whinston, 1986, Free Entry and Social Inefficiency, RAND Journal of Economics 17, 48-58.

[18] Ottaviano, G. I. P. and T. van Ypersele, 2005, Market size and tax competition, Journal of International Economics 67, 25-46.

[19] Perry, M.K., 1984, Scale economies, imperfect competition, and public policy, Journal of Industrial Economics, 32, 313-333.

[20] Sato, Y. and J.-F. Thisse, 2007, Competing for capital when labor is heterogeneous, European Economic Review 51, 2054-2079.

[21] Suzumura, K. and K. Kiyono, 1987, Entry barriers and economic welfare, Review of Economic Studies 54, 157-167.

[22] von Weizsacker, C.C., 1980, A welfare analysis of barriers to entry, Bell Journal of Economics, $11,399-420$.

[23] Wilson, J.D., 1986, A theory of inter-regional tax competition, Journal of Urban Economics, 19, 296-315.

[24] Zodrow, R.G. and P. Mieszkowski, 1986, Pigou, Tiebout, property taxation, and the underprovision of local public goods, Journal of Urban Economics, 19, 356-370. 


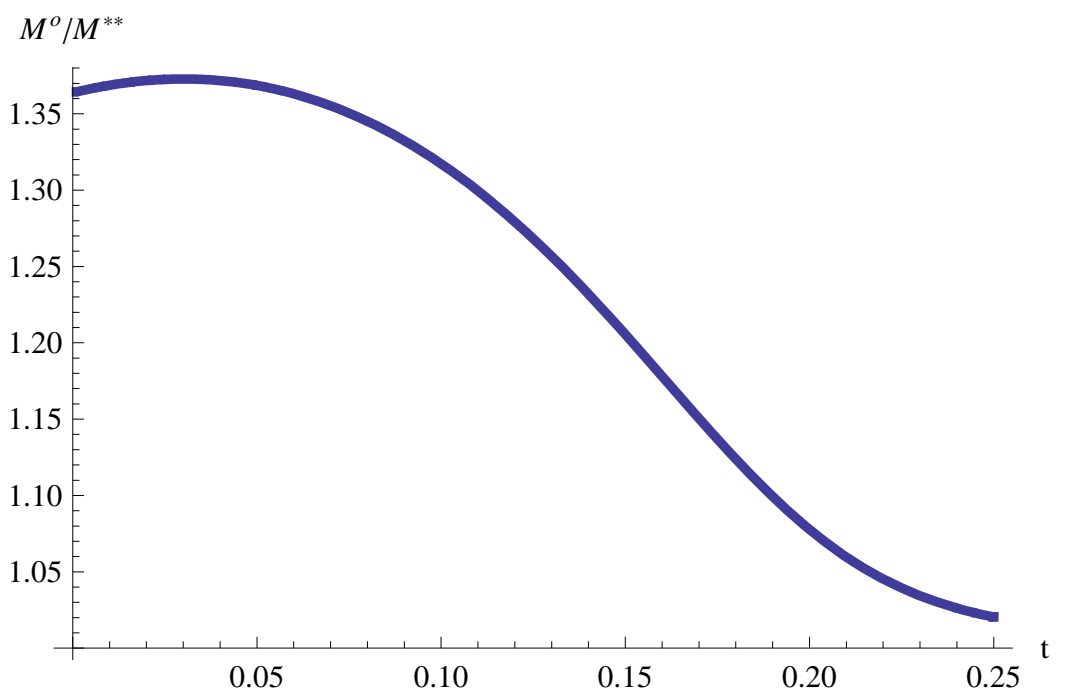

(a) Trade cost and the degree of excess entry

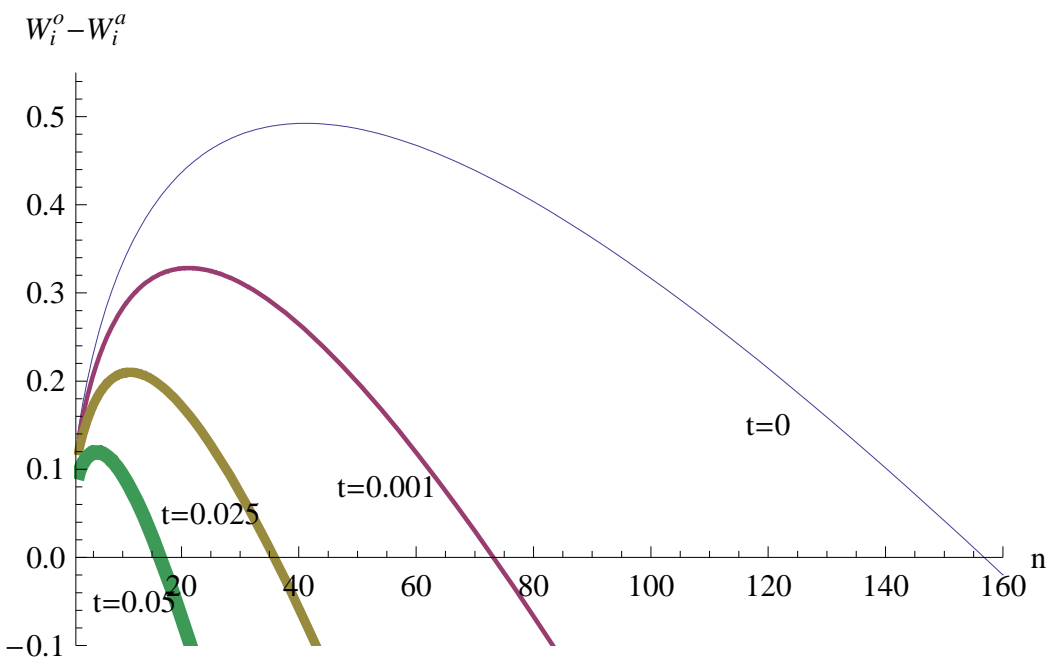

(b)Trade cost and the impact of trade on welfare-(I) 


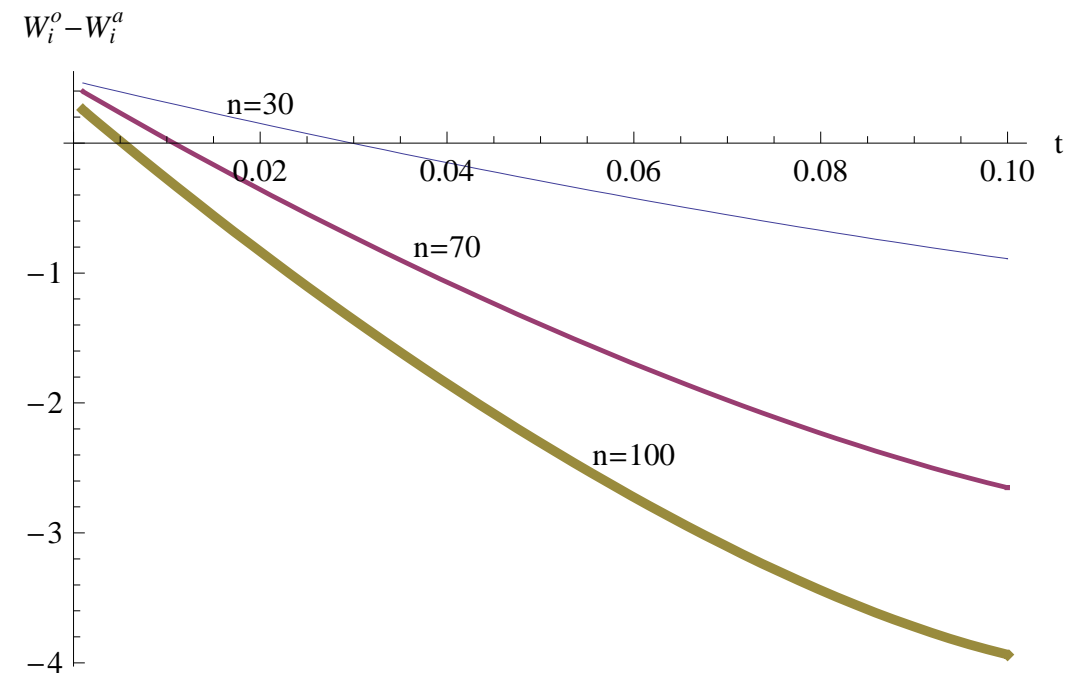

(c) Trade cost and the impact of trade on welfare-(II)

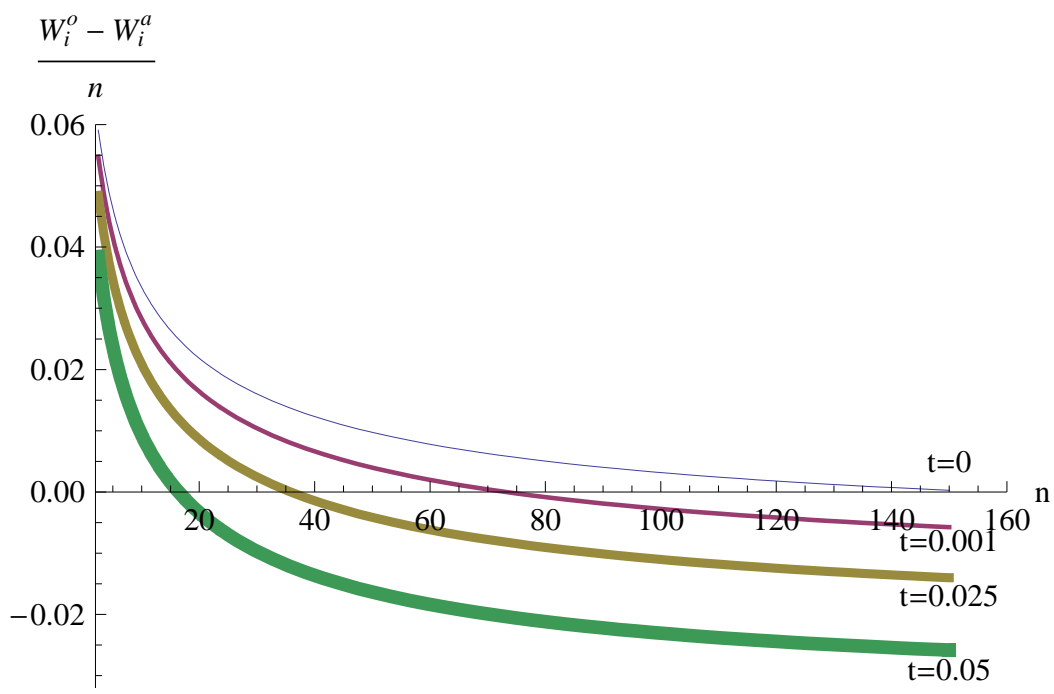

(d)Trade costs and the impact of trade on welfare per capita

Figure 1. Effects of trade cost

Notes: In all figures, we set $k=1$ (i.e., $k_{i}=m_{i} / 2$ ). In (a), we set $n=20$. 


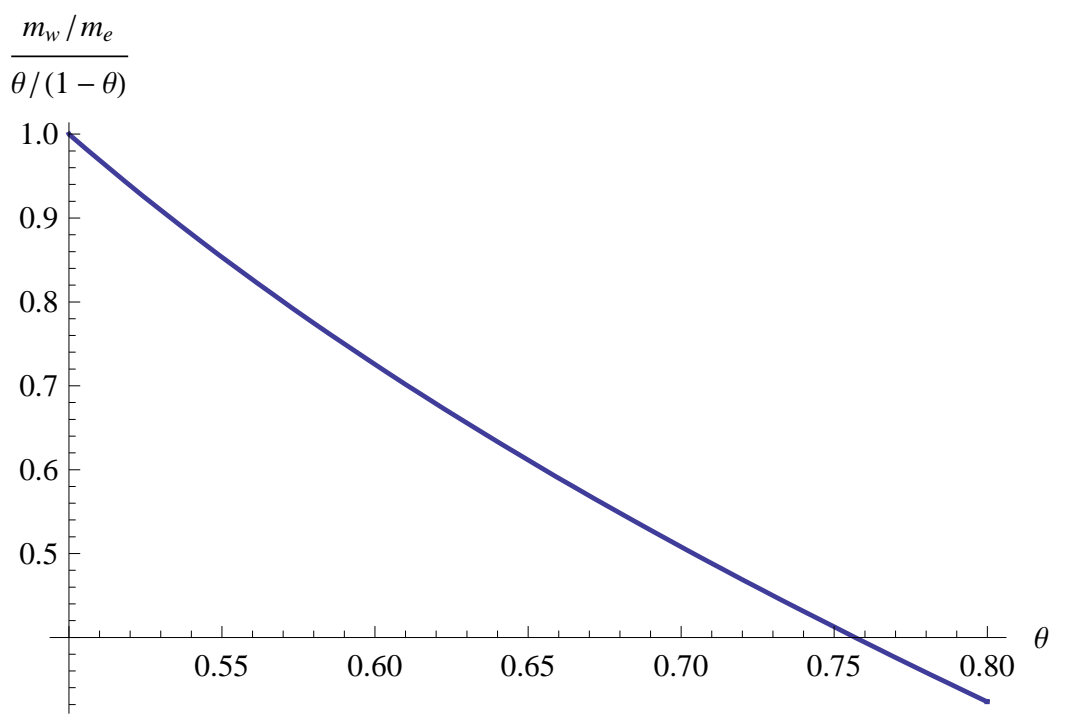

Figure 2. The reverse home market effect 


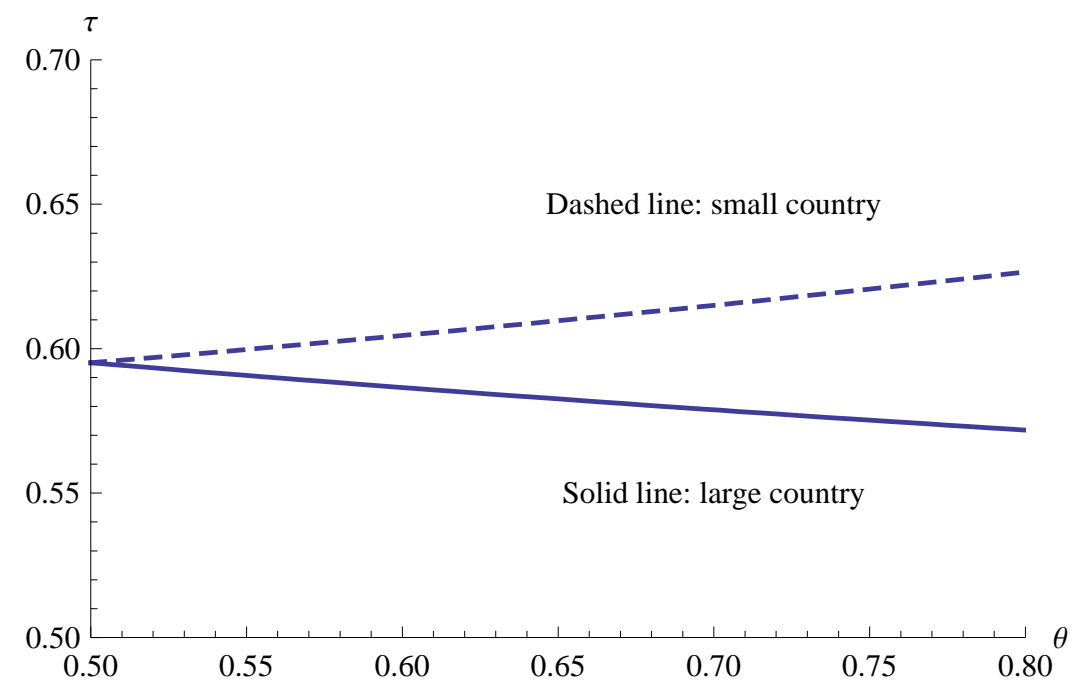

Figure 3. Difference in the tax rate between asymmetric countries 


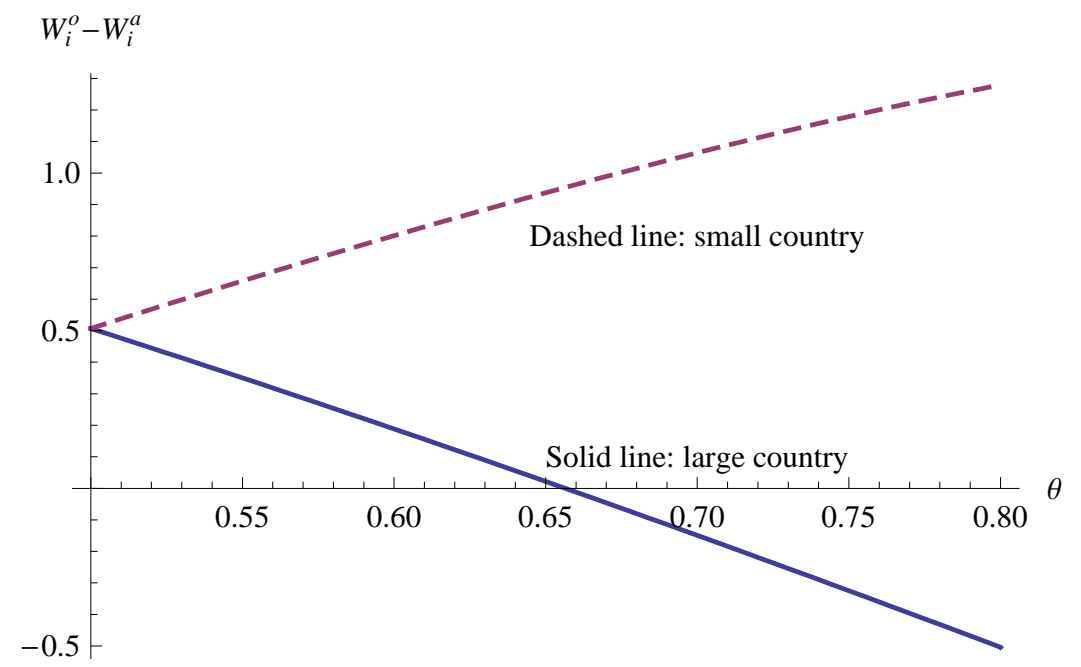

(a) Asymmetry and the impact of trade on welfare

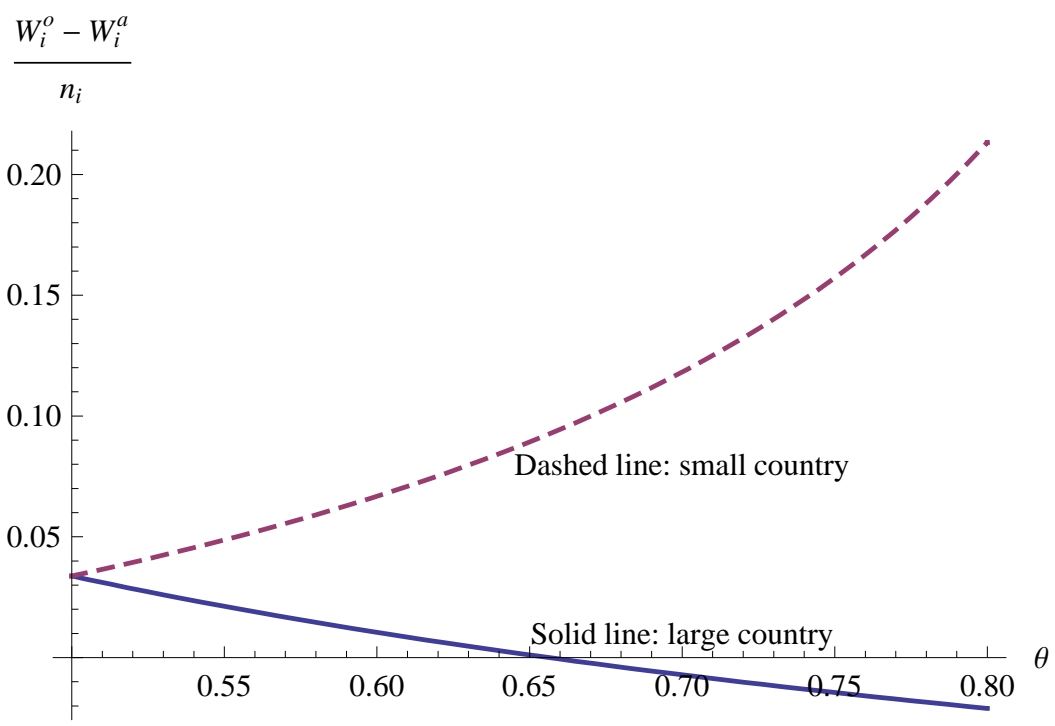

(b) Asymmetry and the impact of trade on welfare per capita

Figure 4. Difference in the impact of trade on welfare between asymmetric countries 